\title{
Universidad e Hispanidad. Tres décadas de trayectorias entrecruzadas del ministro José Ibáñez Martín y el catedrático exiliado Mariano Ruiz-Funes
}

\author{
por \\ Tomás Saorín Pérez ${ }^{1}$ y Yolanda Blasco Gil ${ }^{2}$ \\ Universidad de Murcia y Universidad de Valencia
}

\begin{abstract}
Presentamos la lucha desde el exilio intelectual republicano contra dos de las politicas del franquismo, la reforma de la universidad y la apropiación del término de hispanidad para los fines propagandísticos y proselitistas del nuevo régimen. Estas cuestiones son tratadas a partir de las trayectorias profesionales y vitales de dos politicos destacados, Mariano RuizFunes y José Ibáñez Martín, desde sus inicios en la provincia de Murcia durante la década de 1920, en la cátedra de derecho penal uno y de enseñanza secundaria el otro, su militancia política, los servicios en misiones internacionales durante la guerra y, finalmente, la actividad de uno en la Unión de Profesores Universitarios Españoles en el Extranjero y del otro en el nuevo Ministerio de Educación Nacional y el Instituto de Cultura Hispánica. Centraremos el análisis tanto en los documentos publicados, como en los conservados en los archivos privados de ambos, y que reflejan el conflicto entre las dos Españas.
\end{abstract}

Palabras Clave: exilio republicano español; universidad española; exilio universitario; lucha contra el franquismo; ministros franquistas; Hispanidad.

Cómo Citar este artículo / Citation: Saorín Pérez, Tomás y Blasco Gil, Yolanda, "El debate de postguerra sobre Universidad, ciencia e hispanidad a través de los textos del ministro José Ibáñez Martín y del exiliado Mariano Ruiz-Funes: reconstrucción de tres décadas de rivalidad", Revista de Indias, LXXVII/269 (Madrid, 2017): 263-304, doi:10.3989/revindias.2017.009.

\footnotetext{
1 tsp@um.es ORCID iD: http://orcid.org/0000-0001-9448-0866.

2 yolanda.blasco@uv.es ORCID iD: http://orcid.org/0000-0002-9940-7454.
} 


\section{INTRODUCCIÓN}

Con este trabajo se pone de relieve la relación entre dos figuras de la intelectualidad política española, Mariano Ruiz-Funes y José Ibáñez Martín, en torno a la educación y la cultura durante la primera mitad del siglo XX: ambos profesores, parlamentarios, ministros, publicistas y delegados en el extranjero. Trazamos sus trayectorias vitales, en las que se presentan numerosas similitudes en forma de paralelismos y divergencias, nunca antes puestas de relieve. La relación entre el catedrático de derecho penal Ruiz-Funes y el catedrático de instituto Ibáñez Martín no es la de un enfrentamiento directo: son dos trayectorias independientes marcadas por la sucesión de acontecimientos de la historia española, que al ser observadas de forma conjunta aportan significativos puntos de vista. Encontramos numerosas coincidencias sostenidas en el tiempo, de signo cambiante, y que pueden aportar otra lectura más sobre esa España en la que no había «lugar para esconderse»³. En la segunda parte del trabajo se recogen sus posiciones ideológicas sobre varios temas, a partir tanto de fuentes conocidas - discursos y publicaciones- como a través de documentos privados conservados en sus archivos personales y puestos recientemente al alcance de los investigadores, en las universidades de Murcia y Navarra ${ }^{4}$. Hemos seleccionado dos cuestiones, la de la enseñanza universitaria y la hispanidad, entre 1937 y 1953, sobre las que ambos, desde diferentes ideologías, tienen una experiencia directa, fruto de sus responsabilidades y actividades profesionales.

Acerca de Ruiz-Funes ya han visto la luz buen número de aportaciones. Las dos más recientes: la monografía de Beatriz Gracia Arce, Trayectoria política e intelectual de Mariano Ruiz-Funes. República y exilio; y la nuestra, Las universidades de Mariano Ruiz-Funes. La lucha desde el exilio por la universidad perdida , donde empezaron a tomar forma los materiales que ahora presentamos. Sin embargo sobre Ibáñez Martín no existen trabajos de envergadura, tan solo formando parte de estudios acerca de los gobiernos del franquismo ${ }^{6}$, ho-

3 Ruiz-Domènec, 2009: 974.

${ }^{4}$ El archivo privado de José Ibáñez Martín está depositado desde 2012 en la Universidad de Navarra, Archivo General de la Universidad de Navarra (AGUN), fondo 139. El archivo privado de Mariano Ruiz-Funes se encuentra en el Archivo de la Universidad de Murcia, Fondo Mariano Ruiz-Funes (AUUM, FMRF).

5 Ambas publicadas por la Universidad de Murcia: Gracia Arce, 2014. Blasco Gil y Saorín Pérez, 2014.

6 Entre la bibliografía consultada señalamos: Padilla Bolívar, 2008. Arco y Equipo Mundo, 1971. Miguel, 1975. También información sucinta en diccionarios biográficos como Esperabé de Arteaga, 1956: 247. 
menajes $^{7}$ y referencias aisladas en obras sobre las derechas españolas o la política educativa del régimen. Debido a esta escasez procuramos identificar con precisión las fuentes documentales sobre su trayectoria profesional y política, mientras que sobre Ruiz-Funes nos apoyamos en los trabajos citados.

\section{TRAYECTORIAS ENTRECRUZADAS}

\section{Inicios profesionales y actividad pública en Murcia}

Podemos trazar en paralelo las vidas de Ruiz-Funes y de Ibáñez Martín puesto que aparecen entrelazadas desde sus primeras actividades profesionales en la provincia, su ejercicio como rivales políticos y el desigual destino en el gobierno de la nación. Desbaratado el primero por la derrota y forzado a un exilio lleno de inseguridades. Triunfante el segundo, encargado de dar forma a la educación nacional franquista durante una década desde el ministerio, y reconocido después como uno de los prohombres del régimen. A lo largo de sus trayectorias no dejarán de aparecer ocasiones en las que rastrear sus diferencias políticas y sus enfrentamientos, más o menos directos.

Nacidos ambos en las postrimerías del siglo XIX, con apenas ocho años de diferencia. Ibáñez Martín, el más joven, nace en $1896^{8}$ y Ruiz-Funes en 1889. Este último, tras estudiar derecho y doctorarse en Madrid, estabiliza su posición como catedrático de penal en la universidad de Murcia entre 1915 y 1919, año en que obtiene su plaza. Ibáñez Martín llega al instituto provincial de enseñanza media de Murcia en $1922^{9}$, tras obtener el primer puesto en las oposiciones a cátedra de geografía e historia de instituto. De origen aragonés, nacido en el pequeño pueblo de Valbona (Teruel) y formado con brillantez en la universidad de Valencia, primero en la sección de historia $(1918$, con premio extraordinario) y después en derecho (1921, también premio extraordina-

7 Además de las semblanzas del homenaje del CSIC en la revista Arbor en enero 1970, firmadas por personalidades relevantes de los sucesivos ministerios de educación, como Manuel Lora Tamayo, hay un pequeño volumen poco sistemático, a cargo de su propio hijo: Ibáñez-Martín Mellado, 1998.

8 Tomamos la fecha, 18 de diciembre de 1986, de su expediente personal en el Instituto Provincial de Enseñanza Secundaria. En las breves biografías citadas -Padilla Bolívar, 2008. Arco y Equipo Mundo, 1971- equivocan el año de nacimiento en 1898 y algún otro detalle, incluso considerándolo natural de Murcia.

9 Archivo General de la Región de Murcia (AGRM), IAX, 1307/9, Instituto Provincial de Enseñanza Secundaria, Expediente personal de José Ibáñez Martín (1922-1929). Nombramiento el 14-VI-1922; toma de posesión, 24-VI-1922; cesa el 7-IV-1923 y es confirmado en el mismo puesto desde el 8-IV, por real orden de 19 de abril, con sueldo de 5.000 pesetas. 
rio). Allí había sido «ayudante personal por oposición de Historia de España, Moderna y Contemporánea de la Facultad de Letras», y consta que tiene «aprobadas las asignaturas del doctorado de derecho» ${ }^{10}$.

Los encontramos pues, justo antes de comenzar la dictadura de Primo de Rivera, con 33 años uno y procedente de una acomodada familia de comerciantes de la ciudad de Murcia, y con 26 el otro, recién llegado a esta apacible capital de provincias, desde unos orígenes familiares tradicionalistas ${ }^{11}$ y de hacendado rural ${ }^{12}$.

En los años veinte Ruiz-Funes se dedica por entero a la cátedra y a la consolidación de su pequeña e inexperta universidad murciana. Su paso a la política no se producirá hasta finales de la década. Por su parte, Ibáñez Martín, integrado en los grupos conservadores católicos, pronto tendrá la ocasión de desempeñarse en política, beneficiado del intento de renovación de «la vieja política» que pone en marcha el golpe militar de 13 de septiembre de 1923, al disolver los ayuntamientos y diputaciones. El joven catedrático fue nombrado concejal y tercer teniente de alcalde del Ayuntamiento de Murcia, el 22 de noviembre de 1923. Al año siguiente sería designado por el directorio militar diputado provincial del distrito de Murcia capital, el 20 de enero de 1924 y, al día siguiente, elegido vicepresidente de la comisión provincial. Tras la aprobación del nuevo estatuto provincial será entonces vicepresidente de la diputación, desde primero de abril de 1925. El presidente provincial es entonces José Loustau, quien lo compatibiliza con el cargo académico de rector desde 1924 hasta 1926.

En estos años de mitad de década, Ibáñez Martín fue secretario del Comité Provincial de Unión Patriótica y primer secretario de la Asociación Católica Nacional de Propagandistas (ACNP), en 192513. Para 1926 alcanza la presidencia de la diputación, cargo que ostentará durante unos tres años, entre el 23 de septiembre de 1926 y el 5 de marzo de 1929, y que le proporcionará un puesto nato en la Asamblea Nacional Consultiva creada en septiembre de 1927. Durante este mandato político se le concede la situación de excedencia forzosa, cuyo período no conocemos con exactitud ${ }^{14}$. Al mismo tiem-

10 AGRM, IAX, 1307/9, p. 4.

11 Balbín Lucas, 1970: 13.

$12 \mathrm{Su}$ padre Pedro Ibáñez Val consta como «labrador» en su certificado de nacimiento, y fue alcalde de Valbona (ABC, 23-V-1950), cargo que también ocuparía su hermano Pedro durante el franquismo. Certificado expedido por Antonio Torres Martín, juez municipal suplente de Valbona, 21-IX-1915. Incluido en su expediente, AGRM, IAX, 1307/9, pp. 10-11.

13 Moreno Fernández, 1984.

14 La hoja de servicios de su expediente de personal está fechada el 28 de mayo de 1926, con copia mecanografiada de mayo de 1927, por el secretario Manuel Maza y Ruiz, por lo que podría deberse al inicio de una excedencia. 
po se convoca la oposición en turno de auxiliares para el instituto San Isidro en Madrid ${ }^{15}$, a la que optará desde Murcia y ganará en 1929, bajo el tribunal que preside el conservador Pío Zabala ${ }^{16}$. Renueva su excedencia, con reserva de destino y posición en el escalafón, el 29 de marzo de 1929, siendo ministro Callejo, en tanto continúe «desempeñando su cargo de Presidente de la Diputación y representación en la Asamblea Nacional» ${ }^{17}$. Será en febrero de 1930 cuando se incorpora a su cátedra en Madrid, nada más concluir la última sesión de esta Asamblea, recién dimitido el dictador y adivinándose ya un cambio de ciclo político ${ }^{18}$, tras haber completado una apreciable ascensión social que culmina con la boda en abril con la hija de los condes de San Julián, una de las familias poderosas de la ciudad de Lorca19. Este último año de la década transcurre en un ambiente de contestación creciente al dictador en todos los frentes. Para ambos encontramos un ejemplo del endeble ejercicio del derecho de reunión, alrededor del Casino de Murcia como espacio de sociabilidad, durante la presidencia de Rogelio Manresa. No se autoriza la petición de Federico Salmón y Andrés Sobejano para celebrar un banquete homenaje a Ibáñez Martín por su «triunfo en las oposiciones». De la misma manera son desairados Ruiz-Funes y Martínez Moya en su propósito de homenajear al dimitido rector Loustau. Se quiere evitar que estos actos puedan enmascarar objetivos políticos y producir conflictos con gobernación ${ }^{20}$.

En estos años, en los que Ibáñez Martín se asienta entre los hombres del directorio militar y da el salto a Madrid, será cuando Ruiz-Funes comience su andadura hacia la política. A partir de 1929 se le sitúa claramente en la órbita de Manuel Azaña, con quien estaría desde el primer momento en el

15 La oposición, en turno de auxiliares, se convoca en la Gaceta de 10-VII-1927, aunque se vuelve a anunciar varias veces más, para San Isidro, La Laguna, Cabra y Reus. El 30-IX1927 se anuncia el tribunal, que presidirá Rafael Altamira, exconsejero de instrucción pública, aunque renunciará (Gaceta, 25-I-1928) y será entonces nombrado Pío Zabala, Gaceta 1-II1928).

16 Cesa en Murcia el 14 de marzo de 1929, en virtud de haber sido nombrado para el instituto de San Isidro por real orden de 18 de febrero. AGRM, IAX, 1307/9, p. 17. Señalemos el dato curioso de que su primer nombramiento tuvo lugar, por motivos administrativos, en ese mismo instituto de Madrid en 1922, firmado por su entonces director Manuel Zabala, cuyo hijo había sido ahora el presidente del tribunal de la oposición.

17 Gaceta de Madrid, 29-III-1929, Real orden de 16 de marzo, disponiendo siga en situación de excedente forzoso José Ibáñez Martín, catedrático del Instituto nacional de segunda enseñanza de Murcia, mientras continúe desempeñando su cargo de Presidente de la Diputación provincial de dicha capital y su representación en la Asamblea Nacional.

18 Real orden de 13 de febrero, Gaceta de Madrid, 16-II-1930.

19 Blanco y Negro, 6-IV-1930, p. 106, fotonoticia.

20 Guirao López, 1994: 220. 
partido de Acción Republicana ${ }^{21}$. Para su paso a la política será decisivo el incidente sucedido a Jiménez de Asúa en la Universidad de Murcia, a raíz de una conferencia invitada en 1928, que provocó su sanción y el intento de disolución de la universidad por decreto de febrero de 1929, en un contexto de desórdenes estudiantiles, cierre gubernativo de las universidades hasta abril, y convertida la universidad en foco de oposición al régimen. Ruiz-Funes actuaría a favor de la libertad de cátedra y en defensa de Jiménez de Asúa ${ }^{22}$.

La campaña local que evita el cierre de la universidad, y que trascurre siendo Ibáñez Martín presidente de la diputación, ayudará a la paulatina pérdida de apoyos de la dictadura. En este momento de bisagra entre dos épocas se enmarca el establecimiento definitivo de Ibáñez Martín en la capital, aunque, como veremos, seguirá manteniendo una vinculación importante con las estructuras políticas provinciales conservadoras.

\section{Elecciones, propaganda y política nacional: los años republicanos en Madrid}

El 30 es un año de cambios, y toman cuerpo los nuevos partidos políticos que comenzaron a difundir sus ideas. Ruiz-Funes desde Acción Republicana de Murcia se involucraría de manera decidida en estos movimientos por el cambio de régimen ${ }^{23}$.

Mientras, como miembro de Unión Patriótica y la Asamblea Nacional, Ibáñez Martín, terminado el ciclo de las sesiones de la Asamblea Nacional, se incorpora a la cátedra ganada en el instituto San Isidro de Madrid, posición desde la que asistirá a la caída de la monarquía y al advenimiento de la República entre febrero de 1930 y abril de 1931. Compartirá docencia con otra hornada de profesores que renuevan su claustro, como el geógrafo Juan Dantín Cereceda, el biólogo Enrique Rioja lo Bianco, exiliado tras la guerra, o el matemático Pedro Puig Adam ${ }^{24}$.

El 1 de abril de 1930 participa en la Asamblea de jefes provinciales de Unión Patriótica, donde se decide la creación del partido Unión Monárquica Nacional, al que podrán afiliarse voluntariamente los antiguos miembros del partido títere de la dictadura. Firma el manifiesto que se publica el 5 de abril en la prensa nacional, y formará parte del grupo de políticos que trata de

\footnotetext{
21 Un amplio recorrido por los partidos en los que militó: Avilés Faré, 2006.

22 Sobre el incidente Asúa y el paso a la política de Ruiz-Funes puede consultarse: Gracia Arce, 2014: 33-37 y Valenciano Gaya, 1979: 109-113.

23 Gracia Arce, 2014: 56.

24 Fernández Burgueño y Rodríguez Guerrero, 2011.
} 
posicionarse de cara a las inminentes elecciones, presidido por el Conde de Guadalhorce, como secretario Santiago Fuentes Pila y José Antonio Primo de Rivera, vicesecretario. Ibáñez Martín consta en el secretariado del partido, junto a otros como Ricardo Oreja Elósegui o Julio Palacios. El partido se constituye formalmente en julio de 1930 y allí se codea con Ramiro de Maeztu, Yanguas o Medina Togores. En septiembre de este año lo encontramos en uno de los mítines en Alcázar de San Juan, junto a Dimas Madariaga, José M. ${ }^{a}$ Pemán, Maeztu y el presidente del partido ${ }^{25}$. Su nombre se baraja como candidato por Lorca para las nunca celebradas elecciones legislativas de 1931.

Pero será durante la II República cuando se enfrentarán directamente nuestros dos personajes en las elecciones de 1931 y 1933, e indirectamente en las de 1936, y ambos estarán en el congreso en diferentes períodos. En las elecciones de 12 de abril de 1931, los republicanos triunfan en 41 de las 50 capitales de provincia. Ruiz-Funes se presenta por el distrito tercero en el ayuntamiento de Murcia y sale elegido como concejal ${ }^{26}$. La proclamación de la República llevará a Ruiz-Funes al frente político en primera línea, al ser elegido más tarde diputado en Madrid en las constituyentes. En un primer momento los vientos soplan a favor de Ruiz-Funes, como destacado dirigente provincial del partido de Azaña, presidirá el partido de Acción Republicana en Murcia y llegará a ser su vicepresidente nacional en 1933. Mientras ocupará cargos académicos, como el de vicerrector en Murcia con el rector Loustau ${ }^{27}$.

Aunque Ibáñez Martín forma parte del grupo «cultural» Acción Española, constituida en octubre de 1931, presidido por Maeztu, Sáinz Rodríguez vicepresidente, Vegas Latapie secretario y Javier Vela como tesorero, parece que su participación fue escasa. En la revista aparece mencionado para alguna de las charlas y cursillos previstos ${ }^{28}$, pero ni firma artículos, ni vuelve a ser mencionado. Su proximidad a este grupo conllevará que sea uno de los arrestados tras el fallido golpe del general Sanjurjo en agosto de 1932, lo cual podrá esgrimir a su favor posteriormente como mérito antirrepublicano.

25 Bullón de Mendoza, 2004: 249-251.

26 Gracia Arce, 2014: 60-61.

27 Blasco Gil y Saorín Pérez, 2014: 64-70.

28 En la revista Acción Española, en el número 5, de 16 de febrero de 1932, pp. 96-97, se anuncian «actividades propias de un centro de estudios histórico-políticos. La biblioteca y el salón de conferencias serán los dos ejes sobre las cuales actuará la sociedad. Inmediatamente darán comienzo varios cursillos de diferentes materias a cargos de los catedráticos Sáinz Rodríguez, Goicoechea, Padrera, Artiñano e Ibáñez Martín. Simultáneamente funcionará un círculo de estudios bajo la dirección de D. Eugenio Vegas Latapie». 
Las elecciones de 1933 supondrán un vuelco político importante. En esta ocasión será Ibáñez Martín quien obtenga el escaño compitiendo en la misma circunscripción que Ruiz-Funes. Formando parte del partido de Acción Popular Murciana-CEDA-, es elegido diputado a cortes hasta $1936^{29}$. Ruiz-Funes derrotado vuelve a su cátedra, aunque continúa en política.

Durante el bienio de derechas se recupera Acción Española e Ibáñez Martín aparece consignado como vocal al reinaugurarse los locales de la asociación en mayo de $1934^{30}$. Eugenio Vegas Latapie, secretario, señalará que su inclusión como vocal era meramente testimonial, y lo sitúa más próximo a la derecha de Gil Robles y más interesado en ganar influencia entre los propagandistas y el periódico de Ángel Herrera Oria ${ }^{31}$. Con motivo de un banquete de cumpleaños al rey destaca de él su «no mala oratoria» en comparación con «los trinos decimonónicos» de Esteban Bilbao.

En enero de 1933, en la fundación del CEU en Madrid, figura entre los miembros de la comisión permanente, con el cargo de consejero junto a José Larraz, bajo la presidencia de Herrera Oria y el murciano Federico Salmón como rector -sustituido en 1934 por el marqués de Lozoya-. Sigue formando parte de la comisión en $1935^{32}$. No obstante parece que su papel en política sea subalterno, y que su principal vinculación con la primera fila haya sido, en todo caso, a través del compañero de partido murciano, el abogado y periodista Federico Salmón, ministro de trabajo en 1935.

En el tenso último año de la República, Ruiz-Funes se presenta a las elecciones por la circunscripción de Bilbao con el Frente Popular, donde ganará el escaño. Por su parte Ibáñez Martín repite, sin éxito, por la CEDA en Murcia $^{33}$, donde el único escaño de derechas lo ganará el independiente Agustín Virgili Quintanilla. Ruiz-Funes es llamado por Azaña para entrar en el gobierno, como ministro de agricultura, con la imperiosa tarea de relanzar la esencial reforma agraria, en un clima de urgencia ante las actuaciones de hechos consumados por parte de jornaleros, y la necesidad de «hacer la revolución dentro de la ley» ${ }^{34}$.

29 Moreno Fernández, 1987: 125.

30 ABC, edición Andalucía, 5-V-1934, p. 30.

31 Vegas Latapie, 1987: 357-359.

32 Montero, 1997: II, 533.

33 En algunas obras se sitúan sus orígenes en el partido Renovación Española, si bien no parece que perteneciera formalmente.

34 Sobre este período, Ayala, 1984. Tuñón de Lara, 1985: 166-196. Gracia Arce, 2014: 113-128. 


\section{Misiones diplomáticas durante la guerra}

El alzamiento militar del 36 colocará a nuestros dos personajes en posiciones radicalmente distintas en Madrid. El gabinete de crisis de Casares Quiroga ofrece a Ruiz-Funes encabezar el gobierno, pero no se considera «preparado» para la tarea y lo rechaza. Se encargará entonces de una de las más ingratas carteras ministeriales, la de justicia, aunque por poco tiempo ${ }^{35}$. Por su parte Ibáñez Martín corre peligro evidente, pero consigue refugio en la embajada de Chile ${ }^{36}$. Comparte refugio con José María Albareda, cuyos destinos se unirán pronto. Consigue escapar a la zona nacional en mayo de 1937. Llega hasta Sevilla desde donde viaja hasta Burgos con parte de su familia. En sus acreditaciones se hace constar que pertenecía a Comunión Tradicionalista «desde antes del decreto de unificación» ${ }^{37}$. En el gobierno de Burgos hay oportunidades para su ambición política, como se pone de manifiesto en la siguiente misiva dirigida a su antiguo correligionario en Acción Española, Vegas Latapié:

Querido amigo: Después de diez meses de calvario en la zona roja, en donde el sufrimiento ha adoptado los más variados matices, Dios me ha permitido salir de aquel infierno, para llegar al regalo de la España nacional, en donde para fortuna de todos tan maravillosamente ha prendido el sentido heroico cristiano e imperial de los jubilosos días de nuestra grandeza. Si le sirvo de algo, me tiene Vd. a su incondicional disposición. Un abrazo de su siempre amigo ${ }^{38}$.

Otra coincidencia de las trayectorias es que ambos personajes ocupan puestos similares en misiones en el extranjero durante la guerra. Ruiz-Funes en las legaciones de Varsovia y Bélgica, Ibáñez Martín en Latinoamérica, en la conocida como Misión Cultural del Gobierno Nacional.

35 Gracia Arce, 2014: 129-138.

36 No podemos resistir la tentación de transcribir aquí la placa homenaje propuesta por Andrés Trapiello, «En esta casa y en otras de la embajada de Chile, el diplomático y escritor Carlos Morla Lynch salvó durante los tres años de guerra civil la vida de más de dos mil españoles que se lo agradecieron con el desprecio y el olvido» (Magazine de La Vanguardia, 3 de abril de 2011). En algunas fuentes dice Turquía. Sobre la misión en Chile durante la guerra: Sapag Muñoz de la Peña, 1996 y Morla Lynch, 2003.

37 AGUN, fondo 139, caja 734, la adscripción a Comunión Tradicionalista aparece vinculada al grupo creado entre los refugiados de la legación de Turquía. Hoja de identificación de 16-5-1937; manuscrito que relata su situación personal, presentado en Sevilla y firmado por el capitán de Requetés, 14-6-1937. También se conserva un recibo de mensualidad de Falange de febrero de 1939.

38 Carta de Ibáñez Martín, el 17 de julio de 1937, en Burgos, dirigida a Vegas Latapie, secretario de Prensa y Propaganda, recogida en Vegas Latapie, 1987: 357-359. 
La embajada político-cultural que se organiza desde la Junta Técnica del Estado en Burgos tiene un encargo de propaganda ideológica en las repúblicas americanas, captar adhesiones de la colonia española allí asentada y mejorar la imagen del bando sublevado en la prensa internacional. Ideada por Manuel Arias-Paz y Guitián, al frente del Departamento de Prensa y Propaganda del Cuartel General del Generalísimo, se encarga la dirección al jesuita Francisco Peiró, quien para no ir acompañado únicamente por el poeta y periodista falangista Eugenio Montes, requiere incorporar a otros conferenciantes, que serán finalmente Ibáñez Martín y Ferrán Valls i Taberner, catedrático de universidad de historia de España en excedencia y director del Archivo de la Corona de Aragón. La misión cultural cuenta con un presupuesto generoso que le permite viajar en primera clase, alojarse en los mejores hoteles y moverse en avión entre las ciudades en las que se organicen actos en teatros, estadios, colegios católicos, círculos culturales y sedes de asociaciones ideológicamente próximas.

En Latinoamérica realizan más de 100 actos desde octubre de 1937, en Chile, Brasil, Perú y Buenos Aires ${ }^{39}$, y, aunque no exentos de dificultades, tienen acceso a instituciones y medios de comunicación y cuentan con el apoyo de las delegaciones de Italia, Alemania y Japón. Incluso Ferrán Valls e Ibáñez Martín son distinguidos como doctores honoris causa en derecho civil por la Universidad Católica de Chile en enero de 1938. De la misión diplomática en América queda constancia del contenido de su discurso en la Universidad Católica de Perú ${ }^{40}$, donde expone su visión de «la honda crisis sufrida por el patriotismo español en estos últimos siglos»:

... la política liberal nacida en las Cortes de Cádiz y perturbadora de todo el siglo XIX y el debilitamiento del sentimiento monárquico que dio término a esta institución secular en el año de 1931, sembraron en el alma española toda clase de separatismos, unos geográficos tratando de romper el vínculo secular que unía todas las regiones españolas, y otros en el orden del ideal que del liberalismo desembocó en el socialismo y de éste en el comunismo anárquico y violento que hoy domina en la España roja y que ha escindido definitivamente la nación española en dos grupos: de una parte los sin Dios, los sin patria, sin historia y $\sin$

39 Una descripción detallada de los entresijos de la misión en el estudio preliminar del libro Epistolario de la embajada nacionalista Latinoamericana 1937-1928 (Análisis histórico político e institucional) de Martínez Barrios, 1998: 6-64. También en Sapag Muñoz de la Peña, 2003.

40 AGUN, fondo 139, caja 733, Resumen de primera conferencia sustentada en la U.C. por el Sr. Dr. Ibáñez Martín, "Vocación y destino de España", firmado por L.G.R. de R. Las conferencias tuvieron lugar en Perú entre el 19 y el 27 de diciembre de 1937, y también participaron Eduardo Marquina y Fernando Valls i Taberner. 
cultura que pretendían la desaparición de España, y de otra los que defienden la España tradicional y eterna a la que con sentido de contemporaneidad agregan la justicia social a la gran tarea de la gobernación nacional.

También queda patente la misión diplomática del contenido de la conferencia en el estadio Santa Laura de Santiago de Chile, el 12 de octubre de 1937, donde hablará de la lucha de la «civilización cristiana contra la barbarie roja», porque «el peligro estaba ya acechando a Hispanoamérica» donde «los manejos turbios de las sectas comunistas destruirían su patrimonio espiritual y material $\gg^{41}$.

De la reseña sobre su oratoria se dice: «De sus labios hemos escuchado espléndidos discursos emotivos y eruditos, inflamados de fe, henchidos de patriotismo. Como su maestro don Ramiro de Maeztu, va por el mundo el Sr. Ibáñez haciendo la apología del espíritu hispánico, haciendo revivir el ser de la hispanidad.... $\rangle^{42}$.

Por otra parte, en el bando republicano dada la deserción de muchos de los diplomáticos durante la guerra, el gobierno republicano tuvo que nombrar a personalidades de la universidad y de la intelectualidad para ocupar los puestos que habían dejado vacantes ${ }^{43}$. Ruiz-Funes, fiel al servicio de la República, fue destinado como encargado de negocios en Varsovia, en enero de 1937, y posteriormente pasaría a la embajada en Bélgica. Su salida del país durante la guerra sería reprochada posteriormente por Indalecio Prieto en la prensa en México, provocando su carta-respuesta explicativa titulada "Razones contra golpes", de 1944, donde describe sus difíciles gestiones exteriores en apoyo a la causa republicana ${ }^{44}$.

Mientras, aunque la misión diplomática a favor del bando «nacional» en Latinoamérica continúa hasta julio de 1937 a cargo de otros miembros como Eugenio Montes, el Padre jesuita Francisco Peiró insiste en cumplir con el plazo inicial establecido de 3 a 4 meses y regresa con Valls e Ibáñez Martín a España el 26 de febrero de 1938, donde son recibidos por Franco y Serrano Suñer y felicitados por los informes recibidos de la actividad pro-nacionalista en América ${ }^{45}$.

41 Conferencia en el estadio Santa Laura de Santiago de Chile, del 12 de octubre de 1937, publicada en la revista España y Chile, II/13 (Santiago de Chile, noviembre 1937): 23-25, recogido en Martínez Barrios, 1998: 35.

42 Reseña de Domingo Barbosa, "Uma alta e nobre embaixada", Jornal do Brasil, 6 de febrero de 1938, recogido en Martínez Barrios, 1998: 41.

43 Viñas, 2010.

44 Gracia Arce, 2014: 144-145.

45 Ver reseñas en ABC, Sevilla, 1 de marzo de 1938. 
Ya en España, el Padre Peiró continuará su labor de propagandista con conferencias y artículos sobre la situación en América y la hispanidad. La correspondencia conservada entre ellos refleja cierta distancia, incluso diferentes intereses al establecer sus relaciones y afinidades, aunque públicamente actúen unidos para asegurar el éxito de la misión americana, de la que obtendrán sin duda réditos en el nuevo orden que se adivina ${ }^{46}$. Singular, por su desacierto, es un párrafo de Peiró sobre Ibáñez Martín, en carta al vehemente Valls:

A Ibáñez Martín le he escrito un par de veces y no me contesta. Es superlativa la abulia de este hombre. Imposible que haga carrera en política en estos tiempos en que nadie se acuerda más que de aquel que hace ruido y cuanto más ruido, mejor. Al que se queda en su casa y no habla, ni escribe, ni se mueve, nadie le busca. Como Ibáñez no se corrija, mal porvenir le aguarda. Porque estos tiempos no son como los otros. Que Vd. no procede de esta manera es mi deseo ${ }^{47}$.

No obstante, Ibáñez Martín se incorporará al Ministerio de Interior con Giménez-Arnau, Jefe del Servicio de prensa y propaganda, e incluso consta su inscripción en el registro oficial de periodistas ${ }^{48}$ :

Accediendo a los deseos del Ministro del Interior, me he encargado de la dirección de nuestra propaganda en América, ya sabe Vd. que desde hoy tiene la obligación de ir indicándome cuantas observaciones se le ocurran para mejor éxito de nuestra gestión en aquellas tierras ${ }^{49}$.

Formaría parte del grupo de propagandistas católicos que pronto comenzaría a dar forma al nuevo orden educativo, siendo parte en agosto de 1938 de la Comisión dictaminadora de los libros de texto que se han de usar en las escuelas nacionales ${ }^{50}$. En septiembre asiste al Congreso del partido nazi en Nüremberg, donde queda "verdaderamente impresionado» por «la presentación y formato de todos los actos», y ve a Alemania como «un país puesto en pie y con el que el mundo tendrá que contar para toda obra de verdadera

46 Ferrán Valls volverá en 1941 a la universidad, a la cátedra de historia universal de Barcelona, plaza en la que había fracasado en la oposición de 1933.

47 Carta de Peiró a Valls, Toledo 4 de abril de 1938, recogida en Martínez Barrios, 1998: 140. Archivo Particular Ferrán Valls Taberner, Málaga, L-264/38.

48 AGUN, fondo 139, caja 734, fecha de inscripción, 11-XI-1938.

49 Carta de Ibáñez Martín a Ferrán Valls i Taberner, Burgos, 3 de abril de 1938, recogida en Martínez Barrios, 1998: 139. Archivo particular Ferrán Valls Taberner, Málaga, L-749/38.

50 Diego Pérez, 1999. 
importancia universal» ${ }^{51}$. En este período le encontramos realizando gestiones $^{52}$ para tener preparada y autorizada la reedición, acorde con los tiempos y las ideas del movimiento nacional, de algunos de sus libros de texto de instituto sobre geografía e historia ${ }^{53}$. Esta tarea menor, que pronto sería postergada al acceder al cargo ministerial, contrasta con la que, pocos años más tarde ocuparía a Ruiz-Funes en México para ganarse la vida, haciendo traducciones y ediciones de clásicos de la literatura y el pensamiento, o tratando de ver editados diversos estudios sobre criminología en editoriales comerciales o académicas $^{54}$.

Finalizada la guerra encontramos pues a Ibáñez Martín bien situado en la nueva administración del futuro gobierno, pero encaminado quizá a retomar su carrera docente, tras recibir el nombramiento como director del Instituto Lope de Vega de Madrid ${ }^{55}$. Se tienen pocos datos de los movimientos y rela-

51 AGUN, fondo 139, caja 734, Carta a Justo Formentín, en Castellón, 26-IX-1938. La delegación española estaba encabezada por el general Espinosa de los Monteros, y, entre otros miembros del aparato de propaganda, asistió Antonio Tovar.

52 AGUN, fondo 139, caja 734, Carta de José María Albareda, de 3-XI-1938, desde el Instituto Nacional de Segunda Enseñanza de Vitoria, transmitiéndole la conversación mantenida con el marqués de Lozoya, sobre urgencia de remisión de originales, aunque no estén terminados, para aprobación en próxima reunión de la comisión. Contiene la siguiente frase premonitoria «Dejando la Trigonometría, ¿no estará el éxito en el arte de atar cabos?». Carta desde Burgos, de 9-XI-1938 al Marqués de Lozoya, Subcomisario General del Servicio de Defensa del Patrimonio Artístico Nacional, agradeciendo informe favorable sobre sus obras y observando la conveniencia de ampliar plazos dada «la nueva distribución de las materias de Geografía e Historia». Oficio de 10-XI-1938, a la Comisión dictaminadora de libros de segunda enseñanza, remitiendo sus libros, con indicación de precios. Carta de 14-XI-1938, a Lozoya, enviando original mecanografiado con propósito de dejar dispuesto el material para el curso siguiente. Carta de 22-XI-1938, a Lasso de la Vega, Jefe del Servicio Nacional de Archivos y Bibliotecas, en Vitoria, informando de remisión de manual de Geografía de Europa y otro de Nociones de geografía, de posible aplicación para primer curso de bachillerato, manifestando su deseo de «tener el camino un poco libre, para comenzar la edición de los mismos con vista al próximo curso 1939-40».

53 La obra propia de Ibáñez Martín antes de ser ministro consta, esencialmente, y dejando aparte los discursos como ministro y los prólogos de publicaciones y memorias oficiales, de manuales de enseñanza secundaria: Compendio de geografia universal (1924), Geografia económica y politica (1927), Nociones generales de geografía (1927), Nociones de Geografía de América (1927), Geografia de España (1931), Geografia general y de Europa (1931), Historia de la edad moderna (1935) y Geografía de España (1935). Posteriormente publicó esporádicamente algún estudio monográfico sobre arte y pensamiento.

54 En especial, para las publicaciones de la Secretaría de Educación Popular: Gracia Arce, 2014: 251. La obra científica y profesional de Ruiz-Funes es amplia y ha sido recopilada y analizada en números estudios.

55 AGUN, fondo 139, caja 734, designación como director, abril de 1939. 
ciones personales que le llevarán a la primerísima línea del ejecutivo, aunque parece plausible la influencia de Serrano Suñer ${ }^{56}$. Ruiz-Funes, por su parte, entregará en marzo de 1939 la embajada y la sede de La Casa de España de Bruselas al gobierno belga, puesto que Franco estaba siendo reconocido por los países europeos tras la caída de Cataluña. Acuciado por las incertidumbres del curso de la guerra mundial, abandona Bélgica a principios de 1940 rumbo al exilio americano ${ }^{57}$.

\section{Trayectorias de postguerra: ministerio y exilio}

José Ibáñez Martín es nombrado ministro el 9 de agosto de 1939, sustituyendo a Pedro Sáinz Rodríguez, meses después de su cese-renuncia el 25 de abril. La obra de depuración estaba iniciada, y trazados senderos para «la escuela y el estado nuevo» ${ }^{58}$, pero le corresponderá a él levantar el nuevo edificio del sistema educativo. El ministerio adopta el nuevo nombre de «Ministerio de Educación Nacional» en lugar de «Instrucción Pública» y asume grandes competencias sobre toda la educación, instituciones culturales, prensa, libro, cine y, especialmente, la ciencia.

Su ministerio representa a los católicos y propagandistas, que van ocupando el espacio que pierden los falangistas. Se sostiene en el cargo durante diez años y tres cambios de gobierno en tiempos convulsos - desfascistización, acercamiento a potencias vencedoras, aislamiento internacional...-, lo cual permite marcar con su impronta personal, y la de sus más cercanos colaboradores como Albareda, la intensa reforma educativa del régimen a todos los niveles ${ }^{59}$. Durante su ministerio se aprobará la ley de ordenación universitaria en 1943, los exámenes para excombatientes, la sindicalización obligatoria para profesores y estudiantes universitarios, los institutos laborales y, en especial, la creación por ley de un organismo científico, el Consejo Superior de Investigaciones Científicas (CSIC), en 1940, para el que nombrará como secretario

56 En su archivo privado consta una enfervorecida carta dirigida a Serrano Suñer, felicitándole por su «viaje triunfal» a Italia. Serrano, que había sido también diputado por la CEDA, era ministro de interior y responsable de prensa y propaganda, y artífice de los primeros gobiernos y de los equilibrios de poder entre las familias políticas del primer franquismo. La carta denota haber alcanzado una evidente cercanía; no solo la encabeza con «querido amigo», sino que lo tutea: «tus discursos son para mí de los mejores de tu vida». AGUN, fondo 139, caja 734, carta de 26-VI-1939.

57 Blasco Gil y Saorín Pérez, 2014: 155-157.

58 Sáinz Rodríguez, 1938.

59 Martí Ferrándiz, 2001: 76-92. 
general a Albareda. Fue procurador desde las primeras cortes, 1940-41. La ACNP conseguirá tener un papel importante en la política cultural del franquismo, junto con la falange y el Opus Dei, grupos en los que también será usual que militen los propagandistas. A lo largo de la década será distinguido con múltiples reconocimientos, en razón de su cargo y acumulación de poder, como por ejemplo, de entre una larga lista, el ingreso en la Real academia de jurisprudencia y legislación en España ${ }^{60}$.

Mientras, Mariano Ruiz-Funes en 1940 se exilia a México donde durante más de una década intentará retomar su carrera universitaria, científica y profesional. Impartirá conferencias por toda Latinoamérica, como profesor temporal en universidades de México, escribe varios libros y trabajará para algunos organismos del gobierno mexicano como la Secretaria de Educación Popular. Será uno más de la comunidad de penalistas mexicanos y de la Academia Mexicana de Ciencias Penales desde 1941. Su actividad pública en el exilio estará vinculada al partido de Acción Republicana Española y a Izquierda Republicana, pero pronto pasará a un segundo plano distanciado de las divisiones internas y bandos.

$\mathrm{Su}$ papel de denuncia del régimen franquista lo realizó en varias asociaciones sobre todo en la Unión de Profesores Universitarios Españoles en el Extranjero (UPUEE). También participó en actos sobre cultura y educación, por ejemplo en la Unión de Intelectuales Españoles (UIE). Pero solo en 1950 será cuando consiga un contrato como profesor en la Universidad Nacional Autónoma de México (UNAM) ${ }^{61}$.

La etapa del ministerio de Ibáñez Martín finaliza en julio de 1951, sustituido por Joaquín Ruiz-Giménez (1951-1956), encargado de completar las negociaciones con la UNESCO. Ibáñez Martín deja el ministerio pero consigue quedarse como presidente de honor vitalicio del CSIC. Ahora Prensa-Libro-Cine pasan al ministerio de información y turismo de Gabriel Arias Salgado.

La muerte en el exilio en México de Ruiz-Funes en 1953 cerraría la posibilidad de seguir reconstruyendo estas trayectorias entrecruzadas. La carrera política de Ibáñez Martín continuará quince años más. Sigue de procurador de cortes, miembro del consejo de estado del 51 al 58. Continúa ostentando la presidencia del CSIC hasta 1967 -en que es sustituido por otro exministro de educación, Manuel Lora Tamayo- y vinculado a su revista, Arbor. Recibe múltiples distinciones honoríficas. Fue embajador desde el 58 en Portugal, con

\footnotetext{
60 Puede consultarse su discurso de ingreso en Ibáñez Martín, 1940d.

61 Su trayectoria académica está tratada en Blasco Gil y Saorín Pérez, 2014. La trayectoria política e intelectual en Gracia Arce, 2014.
} 
la delicada misión de enlace con la familia real residente en Estoril, hasta su jubilación y muerte en 1969.

Un último instante en el que podríamos comparar ambas vidas es el de sus funerales. Ruiz-Funes muere en 1953, a su entierro en el Panteón Español en México, D.F., acudieron las autoridades que aún mantenían la ajada ilusión de un gobierno legítimo en el exilio y se realizaron necrológicas y reseñas en prensa $^{62}$. Homenajes entre los que podemos destacar las palabras de insignes personalidades como Jiménez de Asúa o el rector de la UNAM Luis Garrido. Especialmente vívidos son los contenidos como preámbulo a la recopilación de su obra dispersa en el libro editado en Cuba, Últimos estudios criminológicos $^{63}$.

Ibáñez Martín se mantuvo en su puesto de embajador hasta el mismo año de su muerte, a finales de 1969. A su entierro «asistieron las más altas autoridades políticas del Gobierno, presididas por el almirante Carrero Blanco»y, destacan los autores de su reseña como ministro de Franco, que este hecho solo había sucedido «en las exequias del general Agustín Muñoz Grandes» ${ }^{64}$.

62 AUUM, FMRF, 60, 89, Novedades, 3-VII-1953. Reseña la asistencia de «muchos cientos de personas, catedráticos, escritores, amigos y compañeros políticos, mexicanos, que se honraron con ser sus amigos, elementos de la colonia española de todos los sectores...». Asisten entre otros el secretario de educación nacional Ángel Ceniceros, el exrector de la UNAM Luis Garrido, Salvador Azuela, el jurisconsulto Isidro Fabela, el penalista Alejandro Quijano, director del periódico Novedades, el presidente de la Cruz Roja, el general Saravia, el profesor José Giral, Álvaro de Albornoz, la viuda de Manuel Azaña, el general Miaja, el licenciado Portes Gil, el exembajador Nicolás D’Olwer, Recasens Siches, Cándido Bolívar, Honorato de Castro, etc. Se dedicaron actos de homenaje en el Ateneo Español, a cargo del ministro de la república española, Álvaro de Albornoz (Izquierda republicana, XIV/83 (México, junio-julio 1953: 5-6). También acto organizado por la UPUEE e Izquierda Republicana al año del fallecimiento, con discursos de Niceto Alcalá Zamora, Raul Carrancá y Albornoz (FMRF, 60, 94). Así como el acto homenaje, el 29 de julio de 1954, en la Academia Mexicana de Ciencias Penales, con discursos de Teja Zabre, Alfonso Quiroz y Luis Garrido (FMRF, $60,130)$.

63 Blasco Gil y Saorín Pérez, 2014: 253-255.

64 Arco y Equipo Mundo, 1971: 94. Murió el domingo 21 de diciembre. La prensa reseña las personalidades que asistieron a rendirle homenaje (ABC, 23-28 diciembre): representando al jefe del estado, el vicepresidente del gobierno y asisten, entre otros, los ministros del Ejército, Educación y Ciencia, Trabajo, Información y Turismo, Vivienda, Justicia, Asuntos Exteriores y el secretario general del Movimiento, así como varios exministros, el vicario general castrense, el alcalde y el gobernador civil de Madrid. También figuran en las reseñas de prensa: Antonio María Oriol y Urquijo, comisario del plan de desarrollo, Laureano López Rodó, Manuel Lora Tamayo, presidente del CSIC, el exministro de la marina almirante Nieto Antúnez, Alberto Martín Artajo, secretario general del Consejo de estado y Nicolás Franco, exembajador en Portugal y procurador en Cortes. También los exministros José Rubio García-Mina, Joaquín Ruiz Giménez, Camilo Alonso Vega, capitán general, así como el rector de 
El periódico $A B C$ señala que «el ilustre político deja la impronta de su incansable actividad al servicio de España, que le debe la reordenación de la Enseñanza y la fundación del Consejo Superior de Investigaciones Científicas, entre otras realizaciones» ${ }^{65}$. La revista Arbor le dedicaría un número homenaje en enero de 1970.

\section{ENFRENTAMIENTOS DIALÉCTICOS EN TORNO A LA UNIVERSIDAD E HISPANIDAD}

En los apartados que siguen contrastamos, a partir de sus artículos y publicaciones, el pensamiento expresado por Ruiz-Funes e Ibáñez Martín en relación a varios temas culturales y educativos. Ambos proyectan sobre las cuestiones de su tiempo sus posiciones ideológicas enfrentadas en la teoría y la práctica. Su presentación conjunta produce una especie de diálogo imaginado entre México y España que nunca pudo producirse como tal, puesto que la dictadura de postguerra imposibilitó cualquier tipo de disidencia ideológica y debate público ${ }^{66}$.

\section{La lucha por la universidad: las voces del exilio y el control ministerial}

A través del estudio de los discursos oficiales de uno y de los artículos en prensa y revistas mexicanas de otro, podemos conocer cuáles eran sus visiones sobre la situación y necesidades de la universidad española de postguerra. La lucha por la universidad continúa la rivalidad mantenida en décadas anteriores: su denuncia desde el exilio frente a su defensa desde el gobierno, el ideal republicano frente a la universidad nacional católica. ¿Cuál era la situación de la universidad una vez terminada la guerra? Entre la primavera y el otoño de 1939 tiene que improvisarse la puesta en marcha de las facultades, en instalaciones en ocasiones con daños importantes por los usos de guerra, en una situación nacional de penuria económica, militarización de la vida cotidiana y depuraciones. Entre las muchas pérdidas de la guerra se encuentra

\footnotetext{
la universidad de Madrid, el presidente de la Junta de Energía Nuclear, los directores generales del Ministerio de Educación y Ciencia, presidentes de los diversos institutos que integran el CSIC y el arzobispo de Madrid-Alcalá, Casimiro Morcillo. También se celebró una misa en la iglesia de San Roque en Lisboa, con asistencia de embajadores y autoridades.

65 ABC, 23 dic. 1969: 7, al pie del retrato que le hiciera el pintor Enrique Segura, con su atavío de presidente del Consejo de Estado. El 27 se publica nota necrológica firmada por Pedro Rocamora.

66 Lida, 2001.
} 
la de una parte importante del profesorado, exiliado, depurado penal o administrativamente, $\mathrm{y}$ en donde se producirá una renovación apresurada, que propiciará un «asalto a las cátedras» y el establecimiento de las bases de nuevos grupos de poder académico ${ }^{67}$. La guerra y la administración de la victoria provocan una fractura de equipos y líneas de investigación. La temprana creación de un organismo para la investigación, el CSIC, borrará del sistema institucional cualquier referencia a las estructuras previas republicanas de centros de investigación superior, la Junta de Ampliación de Estudios, creando una nueva nomenclatura y nuevas redes de influencia ${ }^{68}$. Por su parte, en México, encontramos un interés similar por el establecimiento de centros de investigación superior, alrededor de El Colegio de México, al que RuizFunes estaría temporalmente vinculado, incluso elevando una propuesta de creación de un Centro de Estudios Penales. Otros exiliados republicanos se integrarían en estos centros de estudios ${ }^{69}$. En España se censuran libertades universitarias como la libertad de cátedra y se establecen mecanismos de control de la comunidad universitaria, bajo un decidido control ministerial. Desde el ministerio, Ibáñez Martín podrá determinar la naturaleza y estructura del sistema universitario y científico español, favoreciendo la dirección y el control por parte de los militantes católicos y, especialmente, del Opus $\mathrm{Dei}^{70}$. Supondrá la entrega a la iglesia del adoctrinamiento moral y control de las mentalidades, tanto de profesores como de alumnos. En un contexto de aislamiento europeo e internacional la universidad será un cauce para aprovechar la conexión hispanoamericana, que legitime al régimen.

La visión del ministro se materializa en sus propios discursos de apertura de curso, en la inauguración solemne de instalaciones y actos institucionales. En ellos están las líneas centrales en las que se basan sus políticas ${ }^{71}$. Resulta aleccionador constatar como ambos personajes coinciden en seleccionar los mismos aspectos críticos de la nueva situación universitaria, como si uno pretendiera desenmascarar la avalancha de retórica del ministro, y éste preparar la defensa ante las previsibles críticas externas injustas en «una coyuntura excepcional en la historia de la cultura española» ${ }^{72}$, y exponer con rotundidad los logros donde el «Estado ha sabido infiltrar su pujante espíritu renova-

67 Blasco Gil y Mancebo, 2010: 201.

68 Puig-Samper Mulero, 2007.

69 Blasco Gil y Saorín Pérez, 2014: 155-176.

70 Alted Vigil, 1991.

71 Trabajamos fundamentalmente a partir de catorce discursos o prólogos publicados entre 1939 y 1950.

72 Ibáñez Martín, 1939: 5. 
dor» ${ }^{73}$. Sin embargo Ruiz-Funes desmonta este lenguaje trascendentalista de la dictadura al señalar que «el predominio del mito sobre el logos, es síntoma de inferioridad intelectual» ${ }^{74}$.

\section{Depuración, selección y carrera del profesorado universitario}

Sobre la selección del profesorado Ibáñez Martín, en su discurso de 1940 «Hacia un nuevo orden universitario», manifiesta la urgencia de la provisión de cátedras vacantes por la guerra, como un «reclutamiento selecto del nuevo profesorado por el sistema justiciero y eficaz de la oposición» para «cerca de doscientas cátedras de enseñanza superior y media, sacadas a oposición durante el transcurso de los pasados meses» y que «estas cátedras no se han otorgado ni se otorgan como premio a las labores heroicas, ni se proveen con un afán inconsciente y necio de llenar huecos, granjeando favores a meritorias actuaciones políticas. Jamás en la vida cultural española se ha exigido a los Tribunales de Cátedras una mayor dureza en la elección de las aptitudes y capacidades $\gg{ }^{75}$. La crudeza de sus propias palabras pone el contrapunto adecuado para entender este especial proceso selectivo: «Habíamos de desmontar todo el tinglado de una falsa cultura que deformó el espíritu nacional con la división y la discordia y desraizarlo de la vida espiritual del país, cortando sus tentáculos y anulando sus posibilidades de retoño». Crudeza que incluso se transforma en brutalidad: «era vital para nuestra cultura amputar con energía los miembros corruptos, segar con golpes certeros e implacables de guadaña la maleza, limpiar y purificar los elementos nocivos. Si alguna depuración exigía minuciosidad y entereza para no doblegarse con generosos miramientos a consideraciones falsamente humanas era la del profesorado» ${ }^{76}$. En años posteriores, 1944, en su discurso "Realidades universitarias", sigue necesitando reafirmar este recambio masivo del capital humano en la ciencia y la universidad - en sus palabras, una «delicada labor», al usar la suave expresión de «rellenar los claros» con «nuevas promociones de estudiosos» $\rangle^{77}$. Estos «claros» son el resultado del proceso de exilio y depuración, que hoy atiende mejor a los términos «atroz desmoche» ${ }^{78}$, aunque para el ministro era un paso para «que las Universidades abrieran sus puertas a las tareas de la

\footnotetext{
73 Ibidem, 1950: XI.

74 Ruiz-Funes, 1944.

75 Ibáñez Martín, 1940a: 11.

76 Ibidem: 9-11.

77 Ibidem, 1944b: 27.

78 Claret Miranda, 2006. Baldó Lacomba, 2011.
} 
paz» ${ }^{79}$. Esta nueva generación es descrita como «jóvenes que han llegado al servicio docente poseídos de una ilusión fervorosa para dar timbres de gloria a nuestro esfuerzo cultural y calidades cristianas y españolas al ejercicio de sus enseñanzas» ${ }^{80}$.

Desde el exilio mexicano, Ruiz-Funes dirigirá sus críticas hacia esta desatinada reconstrucción de la universidad. Dado que el ministro asumía el control de quienes habían de decidir en las oposiciones a las cátedras, las críticas exteriores las podemos entender como personalizadas en Ibáñez Martín al facilitar la introducción masiva de los católicos - propagandistas y miembros del Opus Dei- en las cátedras, remachando el control de la institución a través de una red de personas, que asegurarán la perpetuación del modelo, aplicando el principio de que «los hombres permanecen», pero «las leyes pueden ser derogadas» ${ }^{81}$. En 1947 Mariano Ruiz-Funes describe cómo los profesores fueron no solo depurados sino que «se les exigió, cuando no era posible la sumisión, la neutralidad intelectual, protegida con el silencio ...» ${ }^{82}$. Se hablaba de «oposiciones duras como nunca» ${ }^{83}$ que sin embargo para el exiliado son vistas como una farsa, en la que ya «...no es una Universidad, sino una oficina subalterna de propaganda del régimen». La palabra «propaganda» puede incluso entenderse como un guiño a las competencias en prensa y propaganda que también ejerció el ministro ${ }^{84}$.

En relación a la tarea del profesorado seleccionado, el Ministerio de educación nacional, en fecha tan temprana como 1941 utiliza un lenguaje lleno del espíritu revitalizador joseantoniano, para que la cátedra universitaria no sea una sinecura, un paso en la promoción social. La docencia es una forma de milicia, no solo en su reclutamiento, sino en la forma de desempeñar el puesto como "servicio a la patria», que «excluye todas las concesiones del viejo liberalismo». Se exponen los «ineludibles deberes y la altísima responsabilidad» del catedrático, que «es el jefe docente de su disciplina, el que orienta a sus auxiliares, el que responde, ante las autoridades de la Facultad, de la buena marcha de las enseñanzas; el que ejerce la tutoría científica de los escolares. Precisamente porque se le reclama a un servicio a la Patria de tamaña grandeza, la Ley se preocupa de elevar, hasta el máximo, su categoría social, de determinar sus incompatibilidades y de subrayar la necesidad de su

\footnotetext{
79 Ibáñez Martín, 1944a: 11.

80 Ibidem, 1944b: 27-28.

81 Suárez, 1974.

82 Ruiz-Funes, 1947b.

83 Ibáñez Martín, 1944a: 11.

84 Ruiz-Funes, 1947b.
} 
justa retribución» ${ }^{85}$. Una preocupación similar encontramos en el informe sobre «Proyecto de creación de la carrera del profesorado universitario» realizado por Ruiz-Funes para la Secretaría de Educación Nacional en México: «Es de justicia reaccionar contra la idea que hace de la docencia universitaria una actividad de lujo, una especie de deporte, en el que emplear los ocios de las profesiones liberales, para satisfacer la vanidad de los que hayan alcanzado en el ejercicio de las mismas, posiciones eminentes. La Universidad, si ha de ser eficiente, reclama la total dedicación a ella de todo el tiempo y de todos los afanes de sus maestros» ${ }^{86}$.

En cierto modo hay coincidencias entre ambos en el diagnóstico de muchos de los aspectos que lastraban el desarrollo universitario español. Ibáñez Martín habla de una «verdadera vocación científica y rigurosa formación pedagógica», «un certificado de aptitud pedagógica» o de que «una vez adquirida la categoría profesional, habrá de ser conservada con pleno decoro científico, so pena de jubilación forzosa, por ineptitud o desidia en su ejercicio» ${ }^{87}$. Pero Ruiz-Funes consideraba que ya durante la República se habían «reformado los métodos de reclutamiento del profesorado, con el fin de seleccionar entre hombres dedicados a la investigación, que fueran a la enseñanza superior no a iniciar una obra si no a continuarla y que encontraran en ella el término de una vocación y no su comienzo» ${ }^{88}$. Estos conceptos sobre la docencia, de valor incuestionable, ejercidos dentro de una dictadura y un régimen represor, en realidad dan lugar a lo que Ruiz-Funes expone que sucede «en aquellos sistemas políticos en que está abolida la libertad de pensar

... que convirtieron sus aulas en cuarteles de una milicia política, sus estudiantes en soldados de una milicia cadavérica, y aquellos de sus profesores que no tuvieron el valor de resguardar su dignidad científica y su decoro personal con la marcha dolorosa hacia el destierro, en lacayos de un régimen que arrebataba a la inteligencia sus más elementales atributos ${ }^{89}$.

Por tanto, esos altos enunciados tienen como resultado, para Ruiz-Funes, que la Universidad termine siendo «un nido de favoritismos y lógicamente de la incompetencia... $\rangle^{90}$.

85 Ibáñez Martín, 1941a: 43.

86 AUUM, FMRF, caja 33, Informe enviado el 24 de junio de 1943 a Octavio de Véjar Vázquez, secretario de educación nacional.

87 Ibáñez Martín, 1941a: 42.

88 Ruiz-Funes, 1947a.

89 Ibidem, $1947 \mathrm{c}$.

90 AUUM, FMRF, caja 51, La universidad española actual, documento mecanografiado de 26 páginas, fecha aproximada 1950. Blasco Gil y Saorín Pérez, 2014: 108. 


\section{Nuevo mapa de la universidad y la investigación cientifica}

En los discursos oficiales apreciamos un gran interés por demostrar la inversión en la reconstrucción de las infraestructuras de las universidades y la investigación científica, visto como un «empeño constructivo o de reparación de lo destrozado por la guerra y la barbarie roja» ${ }^{91}$. Podríamos seguir trazando la relación entre ambos personajes a través de sus palabras sobre el número de universidades, un problema lamentablemente cercano a la historia de la universidad de Ruiz-Funes, que estuvo amenazada de desaparecer varias veces. En 1940, el ministro franquista asiste a la apertura del curso en Murcia y a los actos conmemorativos de su XXV aniversario, el mismo año en que se provee la cátedra de penal de Ruiz-Funes, que quedó «disponible» tras su depuración... Ibáñez Martín conocía de primera mano esta universidad y, en especial, la amenaza de desaparición que se volvía a cernir sobre ella en la depauperada situación económica de la postguerra. Ya en noviembre de ese mismo año, en la universidad de Valladolid y ante Franco, exclamaba «Nada de cerrar universidades, necesitamos más universitarios, más bachilleres» y «las universidades de provincias son la esencia más pura e incontaminada de España ${ }^{92}$. En el mismo sentido se manifestaban los exiliados en lo referente a educación superior en la comisión de estudio de los problemas españoles, al afirmar que «aun considerando excesivo el número de universidades existentes en España, salvo casos excepcionales, no estimamos prudente la simple supresión de varias de ellas, sino que sería preferible buscar su agrupación y concentración compensada $\rangle^{93}$.

En 1943 el generalísimo inaugura la ciudad universitaria de Madrid, y el discurso del ministro de 1944 será un inventario de instalaciones y reconstrucción. Pero sobre todo quiere hacer valer la mejora de dotaciones a través del CSIC, que es una de las tareas de envergadura que encara el ministro desde 1940, antes que la ley de ordenación universitaria ${ }^{94}$. Si los republicanos pedían el restablecimiento de la Junta de Ampliación de Estudios, el nuevo estado articula un ordenamiento legal flexible para «heredar unos pocos centros bien tabicados y aislados en Madrid», a los que «abrió, y dilató y creó otros, y desde el primer momento buscó de inmediato contacto con las Universidades españolas para levantar con ellas y con todos los que trabajan, la

91 Ibáñez Martín, 1950: XI.

92 Ibidem, 1940b: 9-10.

93 Blasco Gil y Saorín Pérez, 2014: 413.

94 Para ver la visión de su obra en el Consejo, su prólogo para el libro En camino: guiando una empresa científica (Ibáñez Martín, 1946). Así como en las memorias anuales del CSIC firmadas por él ministro. 
aportación de España a la Ciencia universal». En esta línea hay, sobre el papel, acuerdo entre ambos bandos, puesto que los republicanos planteaban en las conclusiones de la reunión de La Habana de 1943, restablecer «todos los centros de alta cultura e investigación que existían en España antes del actual régimen; ayudar a las Universidades que habían establecido Seminarios, Institutos y Laboratorios de investigación a que los puedan restablecer y desarrollar, organizando una cooperación que los armonice y contribuya a su eficacia ${ }^{95}$.

En 1944, en el discurso "Renacimiento científico en la investigación y la docencia", alaba con su retórica habitual el esfuerzo del estado por dotar a las facultades de nuevos locales, siendo el CSIC el «cerebro y corazón de todo este renacimiento que Franco acaudilla, como la mejor gala de su era pacífica de reconstrucción y mecenazgo», $\mathrm{y}$, como si se respondiera a las críticas de los científicos exiliados, se pregunta «¿Quién podrá decir ya que en España no se trabaja por falta de medios? ¿Quién podrá objetar, como hasta aquí, que el Estado español no tutela con generosidad el desarrollo de la cultura científica» ${ }^{96}$ ?

\section{Libertad de cátedra y de investigación}

La libertad de cátedra será una cuestión importante de crítica desde el exterior. Ruiz-Funes escribía, «el libre juego del espíritu ha sido sustituido por la verdad oficial»; «se han suprimido los heterodoxos, que son la flor más pura de la civilización humana» ${ }^{97}$. Estas frases muestran el grado de indignación y la radicalización de su pensamiento con el régimen franquista ${ }^{98}$. Esta libertad es la que reconocen haber encontrado al retomar su «profesión de enseñanza en la Universidad mexicana donde no existe traba alguna a la libertad de conciencia y de expresión» y que «es, sin duda, el mayor bien que entre otros muchos hemos recibido de este país ${ }^{99}$.

95 Libro de la Primera Reunión de Profesores Universitarios Españoles Emigrados, La Habana, 1944: 98.

96 Ibáñez Martín, 1944b: 13-14.

97 AUUM, FMRF, caja 51, 3 hojas mecanografiadas sin título, inéditas.

98 Recordemos que Ibáñez Martín presidía el patronato Menéndez Pelayo del CSIC para el área de Humanidades, e indirectamente Ruiz-Funes en esta frase estaba citando el título de su obra Historia de los heterodoxos españoles.

99 AUUM, FMRF, caja 43, Copia de carta de agradecimiento al rector Garrido, 14 de abril de 1950, firmada por Rafael Pina, Niceto Alcalá-Zamora Castillo, Mariano Ruiz-Funes y Felipe Sánchez Román. 
Ibáñez Martín pedía a catedráticos y estudiantes «proyectar y difundir la verdad cristiana sobre la faz atormentada del mundo» y afirmaba que «la Universidad de hoy busca con más ahínco la formación del hombre que la del profesional», «es preciso volver hacia la firmeza metafísica de aquello que en la vida íntima del hombre tiene más profundas raíces espirituales» ${ }^{100}$. El concepto de «ciencia española» y «ciencia cristiana» es uno de los que más enervan a los científicos exiliados, como un regreso a la contrarreforma, al aislamiento intelectual o la singularidad hispana que la tiende a alejar de las corrientes de la comunidad académica internacional ${ }^{101}$. La incorporación de las directrices y vigilancia religiosa se considera un lastre para el sistema científico, y Ruiz-Funes sostiene que para la universidad de Franco «vale más un creyente que un investigador» ${ }^{102}$.

La idea de controlar la universidad queda patente en Ibáñez Martín en su discurso "El sentido político de la cultura en la hora presente", en el curso 1942-1943 de la Central103, donde insiste en el nacionalcatolicismo. Hay que regenerar al hombre en la fe y la obediencia es virtud imperial, en la jerarquía y disciplina. El servicio como virtud individual del trabajo y de la inteligencia. La política educativa franquista busca conseguir la estabilidad del régimen y «es inexcusable el signo cristiano y antiliberal de nuestro Movimiento y permanente su designio de revolución». La acción educadora es el principio de la estabilidad, debe haber unidad de pensamiento en una doctrina única y unidad en el sentimiento. La cultura debe ser el instrumento más importante del resurgir nacional. En cuanto al deber de la ciencia: «El régimen necesita una falange intelectual y docente» aunque conscientes de que «de nada sirven las leyes sin los hombres que las ejecuten y las cumplan con rectitud y con patriotismo». Hay, según él, en este fin una ética docente universitaria: «La recristianización y la renacionalización de la enseñanza es obra total y empresa colectiva», que exige el estado. El deber de la juventud es formarse en los principios del estado:

De aquí que el deber formativo que ante todo se acusa en el plano de la vida docente como un postulado nacional, abarque a todos los españoles para que en grado unánime todos se sientan responsables del destino histórico de la Patria ... Son por ello los Catedráticos españoles nuevos cuadros de choque de esta milicia de la cultura que Franco, genialmente, ha sabido poner en pie.

\footnotetext{
100 Ibáñez Martín, 1944a: 33-35.

101 Otero Carvajal, 2006.

102 AUUM, FMRF, caja 51, Esquemas y anotaciones para un trabajo sobre Misión de la Universidad.

103 Ibáñez Martín, 1942.
} 
Tras la retórica de la formación en valores, la formación de la persona integral que formula la ley de 1943, Ruiz-Funes aprecia en realidad la pérdida de un valor esencial en la comunidad científica, dado que «a la influencia intelectual ha sustituido la influencia política». La universidad se convierte entonces, sobre todo, en una maquinaria de poder y control social, y no un espacio consagrado al saber.

Por otra parte, serán más los aspectos de la universidad sometidos a crítica desde el exterior: como la libertad de cátedra y de investigación, el control de la iglesia o la destrucción de escuelas y tradiciones ${ }^{104}$. Ruiz-Funes, en Las Españas, criticó la orientación de la Universidad:

...la defensa de la unidad religiosa de España, sin duda porque allí se han desencadenado cuentas e implacables guerras de religión. Sus profesores y alumnos constituyen una milicia, a la que la ley pertinente la llama nada menos que el ejército teológico para combatir la herejía.

Estamos, dice, ante una nueva Inquisición, la iglesia y la falange, que vigilará la enseñanza y controlará entre otros los libros prohibidos. Y en el mismo sentido denunciaría ante la UNESCO que «no es posible realizar una investigación científica simplemente decente y docente, es decir con decoro y valor pedagógico, si no la asiste la libertad» ${ }^{105}$. La voluntad de control centralizado desde el gobierno se despliega también sobre los investigadores del CSIC, ante quienes proclama Ibáñez Martín «que será vana nuestra cruzada científica y que volveremos a un régimen de saber insociable y anárquico, si no jerarquizamos nuestras actividades, subordinándolas al principio supremo y unificador de la Filosofía»; una palabra noble que se usa para controlar una ciencia «española y católica», la cual «no estará jamás en pugna con la fe, que, precisamente por ser ciencia total y plena, cumplirá el destino agustiniano de vivir en las cercanías de la Divinidad» ${ }^{106}$.

\section{Balance de una década}

Ruiz-Funes afirmaba que algún día en el futuro tendría que hacerse la acusación razonada contra la agresión que se había hecho, tras la guerra, contra una universidad, la republicana, «a punto de lograr, cuando inició su

\footnotetext{
104 Blasco Gil y Saorín Pérez, 2014: 328-353.

105 Ruiz-Funes, 1952. Original mecanografiado en AUUM, FMRF, caja 11, Principios universitarios, 3 páginas.

106 Ibáñez Martín, 1940c: 9-10.
} 
asolamiento la barbarie, una ejemplar plenitud» ${ }^{107}$. En buena medida esto ha tenido lugar en numerosos estudios académicos. Sin embargo, con el cambio de década podemos ver cómo ambos personajes realizan un balance de la situación.

En Ibáñez Martín se personifica la primera década de la universidad de postguerra, puesto que ocupa el ministerio sin interrupción de 1939 a 1951 . Si él resumió de forma grandilocuente el alcance de su obra como «diez años al servicio de la cultura española», de cuyos resultados responde como artífice máximo fruto «del trabajo medido, del estudio y de la reflexión más ponderados. Nada de lo que en este aspecto se ha hecho es hijo de la improvisación ni consecuencia de la osadía irresponsable, que construye efímeramente, sin voluntad de prevalecer en el porvenir». Estas palabras suyas sirven de balance y juicio ${ }^{108}$ :

Si en el orden de la investigación fue preciso «corregir el divorcio y la discordia que existían entre las ciencias especulativas y experimentales y provocar el desenvolvimiento armonioso y la evolución homogénea en el árbol de la ciencia», en la nueva Universidad se sumó a la función docente, la de crear la ciencia misma, la de educar a la juventud para la vida y la de regir y orientar todas las ramas de la cultura y de la enseñanza.

Ruiz-Funes presenta un cuadro con otra paleta de colores: «La azul uniformes, ruidos de botas en los pasillos, rigidez en los ademanes, brazos tendidos, himnos, recuerdos a los caídos, terror en los claustros, germanofilia desbordante, nazismo; una minoría, de excombatientes en su mayor parte, se impone en la Universidad por la fuerza. La negra sotanas, misas de solemnidad, imperio de la recomendación y del favoritismo, maneras suaves, vigilancia estrecha, ejercicios espirituales universitarios. Hoy estamos en la segunda etapa $\gg{ }^{109}$.

Los universitarios exiliados hacían este otro balance en su denuncia ante la UNESCO, en vísperas de la primera Conferencia internacional de universidades de Niza en 1950:

La degradación de la Universidad española ha sido consumada por una ley del nuevo Estado. En ella se declara que la misión de la Universidad, de acuerdo con una frase del cardenal Cisneros, es «honrar a España y servir a la Iglesia», con lo que se consagra su carácter confesional. Se la llama «la gran Universidad imperial» (del imperio nacional-sindicalista). Se declara preceptiva la cultura religiosa. Se

107 AUUM, FMRF, caja 51, La universidad española actual.

108 Ibáñez Martín, 1950.

109 AUUM, FMRF, caja 51, La universidad española actual. 
afirma su carácter nacional-sindicalista. Se la titula la «falange misionera del catolicismo». Se prescribe que ha de ajustarse a los puntos del programa de Falange, el partido político único. Se incorporan a todas sus Facultades cuatro cursos de religión. Se declara forzosa la sindicación única de profesores y estudiantes. Se militarizan los últimos. Se crean Colegios Mayores y cátedras especiales para explicar el único pensamiento político tolerado. Al término de la guerra civil, en 1939, declaró el Ministro de Educación, en la ceremonia de apertura de cursos en la Universidad de Madrid, que «se acabó para siempre la libertad de cátedra». Junto a la esterilización de la Universidad, figura corrupción, que la ha convertido en un nido del favoritismo y de la incompetencia ${ }^{110}$.

\section{La hispanidad: propaganda imperial frente a experiencia vital}

Otro lugar en que confluyen ambos personajes será el de la hispanidad, en su vertiente tanto de concepto cultural como de instituciones culturales españolas en América. El intento por comprender España y lo español se convierte en una preocupación entre los exiliados que la sienten lejos, espacial y emocionalmente. Influirá en que la cultura española y las americanas sean entendidas como un flujo de influencias mutuas, y el hispanoamericanismo de los exiliados se alejará del paternalismo tradicionalista del hispanismo peninsular ${ }^{111}$. En el lado nacional, la construcción de un discurso que de trascendencia al régimen se irá apoyando en un conglomerado de ideas y modelos, moldeadas con sentido práctico: cuando el lenguaje fascista y germanista parece poco sólido, se disfraza el armazón institucional con ropajes de derechos, justicia social y fueros ${ }^{112}$. La política exterior del régimen oscilaba según el curso de los acontecimientos internacionales. Si una idea podía molestar a las potencias, se matizaba, como sucederá con la hispanidad, el vínculo americano, que será uno de esos espacios transitables en los que los hombres de Franco buscan oxígeno y crédito exterior. Alrededor de la hispanidad ya habían construido sus trincheras y cuarteles de invierno los tradicionalistas y conservadores en los años treinta. Ahora será además un instrumento al servicio de un proyecto ${ }^{113}$. El falangismo llenó de pompa y providencialismo el concepto de hispanidad, sintonizando con las clases conservadoras americanas -de origen español o criollas- como alternativa al protagonismo de la influen-

110 AUUM, FMRF, caja 51, Copia de carta dirigida por la UPUEE, firmada por José Giral (presidente) y Niceto Alcalá Zamora-Castillo (secretario), fechada el 1 de diciembre de 1950, con manuscrito hológrafo de Ruiz-Funes. Lleva anotación posterior a lápiz de su hija que indica «Elaborado x Ruiz-Funes».

111 López Sánchez, 2013.

112 Pérez Montfort, 1992.

113 Marcilhacy, 2014. 
cia norteamericana, favoreciendo inicialmente la acción propagandística española ${ }^{114}$. Pronto, el acercamiento a los aliados, desaconsejaba continuar con la presencia del falangismo en el servicio exterior, y fue sustituida por la acción cultural. La elaboración del concepto hispanidad, tomando a Ramiro de Maeztu como referente, en su «interpretación católico-tradicionalista de la identidad nacional española», será la doctrina oficial del régimen para política internacional ${ }^{115}$ para sortear el aislamiento diplomático ${ }^{116}$, tapando el inmediato pasado filofascista. En las postrimerías de la guerra civil, desde sus funciones en prensa extranjera, en el Servicio nacional de prensa, Ibáñez Martín refleja la visión de la situación española como tendencia y ejemplo para la «comunidad hispanoamericana» 117 :

Felizmente España ha terminado su guerra con la victoria definitiva de la espada de Franco sobre las turbas bolcheviques que querían aniquilar nuestro patrimonio espiritual. España en su calidad de defensor de la civilización occidental y de la comunidad hispanoamericana ha cumplido una vez más su sagrado deber de orientar y dirigir en momento tan difícil para el mundo.

En julio de 1940, Ibáñez Martín participa en el ciclo de conferencias «Voces de la hispanidad», organizado por la Asociación Cultural Hispano-Americana y emitido por Radio Nacional para «los pueblos de América» ${ }^{118}$. El hispanismo no ha de ser para el franquismo simplemente «un tópico de innovación sentimental en determinadas fiestas conmemorativas del año», sino un recurso para un fin, que el ministro expresa en términos de responsabilidad histórica por el lazo indestructible de haber «dado vida a unos pueblos, enseñarles a hablar un mismo idioma, a vivir idénticas costumbres y a rezar a un mismo Dios». España, «madre de pueblos», tiene la misión histórica de influir en el desarrollo de las naciones que hizo surgir. En su visión, el «sacrificio» doloroso realizado por España ha de servir para una «expansión espiritual» en Hispanoamérica que «no ha querido olvidar el sentido de su tradición y que sitúan en el plano primordial de sus preocupaciones la conservación y la jerarquía de los eternos inmutables valores del espíritu», frente a los países

114 Arenal, 1994: 29-68.

115 González Cuevas, 2008: 618-619.

116 Portero, 1989.

117 AGUN, fondo 139, caja 733, carta de 28 de abril de 1939, en relación al Congreso internacional de juventudes de acción católica que se celebrará en Lima, dirigida a José de la Riva-Agüero de Osma, abogado, intelectual católico y político conservador peruano, vinculado a la Universidad Católica de Perú. Había sido en años anteriores presidente del consejo de ministros y ministro de justicia, destacado defensor de los regímenes fascistas.

118 Ibáñez Martín, 1941b. 
que «labran la ordenación de su vida política y social con un criterio materialista, donde juega principal papel la ley del egoísmo económico», paráfrasis del socialismo y el comunismo. Al lector de hoy, conocedor de la penuria generalizada de medios de subsistencia y trapicheos ya en el año1940, le produce algo de rubor leer como rechaza a quienes tienen «la decrépita concepción de los que solo tienen como nervio de sus actos la lucha por un torpe y grosero bienestar material» y no «los valores eternos» que la nueva jerarquía maneja con soltura y voces estentóreas. España apremia a que «nuestros hermanos de América» emprendan «abrazados estrechamente en unidad de afanes con nuestra Patria, la magna cruzada de espiritualización del mundo» ${ }^{119}$.

Aunque durante la guerra civil se habían activado las embajadas culturales, vinculadas a la Falange, desde 1942 se apostará por el «bloque ibérico» con Portugal y el «hispanoamericanismo estrictamente cultural» y un intento de acercamiento al Vaticano ${ }^{120}$.

En el lado opuesto, la actividad de contra-propaganda realizada por los exiliados tenía como destinatarios a «el mundo civilizado», y trataba de despertar apoyos «preferentemente la América Hispana» dado que «nos acompaña en la devoción entrañable por nuestra cultura, conozcan este insólito atentado, que se consuma en horas llenas de esperanza, cuando se está consolidando la reconquista de la libertad» ${ }^{121}$. En 1943 Ruiz-Funes no bromea sobre el uso político de la hispanidad por parte de Franco, lo considera «una forma de la conducta criminal», realizada por España por necesidad de la maquinaria de propaganda alemana, que «necesitaba una fuerza neutral no sospechosa, que viniera a América a extender por todas partes sus mitos y esa fuerza la encontró detrás de esta palabra hispanidad, palabra bárbara de origen teutónico, bajo la cual se han encubierto las actividades de ciertos Quislings» ${ }^{122}$. Esa hispanidad, esencialmente concebida como tapadera noble al servicio de la dictadura, es repudiada por la intelectualidad:

En nombre de hispanidad se han hollado las virtudes predominantes del genio español: su sentido de la justicia, la universalidad de su pensamiento, la grandeza de sus conceptos jurídicos, el valor ecuménico de su civilización ${ }^{123}$.

119 Ibidem: 214-215.

120 Pardo Sanz, 1994: 271.

121 Boletín de la UPUEE, 1 (México, agosto 1943): 8.

122 Así se expresa en uno de los discursos solemnes a su cargo en la Primera Reunión de La Habana de Profesores Universitarios Españoles Emigrados, recogido en Boletín de la UPUEE, 5, México, 25 de septiembre de 1943.

123 Idem. 
A finales de 1945 se transforma el Consejo de la Hispanidad en el Instituto de Cultura Hispánica, controlado de cerca por el Ministerio de Asuntos Exteriores «cuyo control no causara problemas internos, ni siguiera estando mal vista por la opinión pública latinoamericana» ${ }^{124}$. El instituto contará además con abundantes medios. Se crea un departamento de publicaciones y se presta atención al intercambio bibliográfico con la América hispana -en el mismo sentido que el CSIC. Se desarrollará un departamento de «misiones culturales» y se crearán sedes en diferentes países. No obstante, hasta que la coyuntura internacional no se vuelva claramente anticomunista, a partir de 1947, sus acciones tendrán escasos efectos prácticos ${ }^{125}$. El uso de la coartada cultural para una actividad fuertemente politizada por la diplomacia también encontró resistencias por parte de hispanistas del continente ${ }^{126}$. Tanto en el ministerio de exteriores como en el de educación son conscientes de que tienen que «vencer la todavía fuerte repugnancia de muchas instituciones americanas a trabar contacto y relación con organismos oficiales españoles» ${ }^{127}$.

En la otra orilla del Atlántico, en 1948, en la revista Las Españas se alertaba acerca de la intención de Franco de crear Institutos de Cultura Hispánica, al amparo de la idea de hispanidad ${ }^{128}$. El Instituto de Cultura en México no se pudo inaugurar por la presión de los exiliados. Desde ésta, y otras revistas, se movilizó a la emigración contra el Instituto impidiendo que funcionara ${ }^{129}$. El nuevo intento de Sánchez Bella, nuevo titular de la Dirección de cultura hispánica, de crear un Instituto en México estaba condenado al fracaso.

Y contra la llegada a las repúblicas americanas de emisarios culturales españoles se movilizarán los profesores de la UPUEE en los medios de comunicación, actuando de contrapeso en la opinión pública. Desde España fueron comisionados profesores e intelectuales aceptados por el régimen, de diferente talla y trayectoria, pero todos recibieron el rechazo de la comunidad

124 Delgado Gómez-Escalonilla, 1992.

125 Pardo Sanz, 1994, 271-278.

126 Cañellas, 2014.

127 AGUN, fondo 139, caja 569, Carta de 13 de julio de 1949 del Instituto de Cultura Hispánica, al Ministro de Educación Nacional, solicitando la concesión de una licencia para una emisora de radio vinculada a la revista Mundo Hispánico, con anotación manuscrita del ministro denegando la petición.

128 "Un Instituto Hispánico AMGD” y "Encuestas sobre la penetración franquista en América", Las Españas, 10 (México, septiembre 1948) y también se alertaba en el núm. 11 (enero 1949).

129 Valender y Rojo Leyva, 1999. Caudet, 1997: 293-299. 
exiliada por prestar su figura y obra en apoyo de la dictadura130. Encontramos un cuestionario respondido por Ruiz-Funes sobre la «significación de la fundación del Instituto de Cultura Española en México» ${ }^{131}$, inaugurado en 1948 por Ruiz-Giménez ${ }^{132}$, publicado sobre el rótulo «Del imperio azul a la hispanidad». Ruiz-Funes, parafraseando un memorándum de la Unión de Intelectuales españoles en México, califica la fundación del Instituto como «avanzadas del falangismo en América» y «penetración católica e imperialista en las democracias americanas». También se critica la dedicación del exiguo presupuesto del estado español a la propaganda exterior. Acusa a los invitados por el instituto a participar en eventos culturales en España de hacer «turismo intelectual», colmándolos de «deslumbrantes elogios» y poniéndolos «en contacto con los intelectuales del régimen que producen respuestas orquestadas o cuyas manifestaciones auténticas deforman los que las perciben, por sectarismo o por no pecar de descorteses y los devuelven a sus patrias con el ruego de que digan algo. Algunos de evidente autoridad se callan». Sobre la representatividad de la cultura española por la nueva institución, se muestra contundente alineando a Franco con los líderes derrocados:

Hay que evitar confusiones. Nada tenemos que ver con la nueva Institución los republicanos españoles que vivimos en América. Ella no es para todos los españoles, como no sería para todos los franceses la que hubiera creado el ex-Mariscal Pétain, ni para todos los italianos la que fundara el extinto Mussolini.

Como vemos, se presenta un nuevo teatro de confrontación entre republicanos y franquistas, esta vez en los países de acogida del exilio. Por este motivo Ruiz-Funes propuso, en nombre propio y sin actuar en representación de ninguna sociedad de intelectuales, «responder a cada acto del falangismo intelectual importado con otro de la inteligencia libre española». También señaló la sintonía entre parte de la colonia española con el discurso tradicionalista del franquismo. A través de este centro cultural, el franquismo «ha dejado sus crías al abrigo de un sector de la vieja colonia, embaucada con cintajos que simbolizan «espirituales» encomiendas; ha cobrado doscientos mil pesos de un solo «encomendero», y todo en marcha ya, ha vuelto a Es-

130 Autores de la talla de Dámaso Alonso son tachados de «serviles», recuperando el lenguaje fernandino. Daniel Tapia, 1949: 15.

131 Breve nota de Mariano Ruiz-Funes, titulada "Encuesta sobre la penetración franquista en América”, Las Españas (México, septiembre 1948): 12.

132 Ruiz-Giménez sería el primer presidente del Instituto, aunque pronto pasaría, en 1948, a ocupar el cargo de embajador ante la Santa Sede y, de ahí, al mismo Ministerio de Educación en 1951. 
paña en busca de las momias intelectuales que «están» con el franquismo, futuros misioneros de una cultura venenosa, asalariada, mortal para los hombres y los pueblos» ${ }^{133}$. Las actividades republicanas se harán con más voluntad que medios - «sin asistencia alguna del capital español hecho en América»-, puesto que les «sobra calidad para anular los residuos imperialistas y pedagógicos del franquismo adulado por las democracias ${ }^{134}$. Sus actividades ya no solo están orientadas al país que dejaron atrás, sino que se integran en la vida civil en sus países, por lo que no tardarán en tomar forma instituciones republicanas culturales, cuyo mayor exponente en México será el Ateneo Español. Podemos seguir el curso de las reflexiones de Ruiz-Funes sobre la ausencia, durante los años de la emigración a América de los años 20 y 30, de un centro de cultura que sirviera de «vínculo de unión a la emigración intelectual» 135 :

Nos ha faltado a los españoles el gran centro intelectual que hubiera consolidado para el futuro la colaboración fraterna de nuestra patria y de la América que habla y piensa en español; e incluso no hemos dispuesto del gran órgano de expresión de esa élite hispanoamericana, de una gran revista o de varias revistas de especialidades... Ha faltado el Instituto de Altos Estudios Hispano-Americanos y su órgano científico ${ }^{136}$.

La UPUEE tomará interés por la cuestión de la construcción de una red universitaria y cultural de ámbito latinoamericano. Sus miembros estuvieron detrás de estos esfuerzos por mantener una cultura republicana, española y abierta en el exilio. No obstante ya ven a la universidad española como irrecuperable:

Si ahora debiéramos preguntarnos cómo ha de ser en España la Universidad del futuro; tendríamos que plantearnos forzosamente una cuestión previa: la necesidad de aniquilar radicalmente -hasta sus raíces- la Universidad del presente, que, recordando una frase muy conocida de dos psicoanalistas eminentes, Alexander y Staub, se ha convertido en «el vertedero de todos los sadismos» ${ }^{137}$.

133 Columna sin firmar, titulada "Un Instituto Hispánico A.M.D.G." con referencias a la influencia de los jesuitas, Las Españas (México, septiembre 1948): 12.

134 Idem.

135 AUUM, FMRF, caja 51, 3 hojas mecanografiadas sin título. Con anotación posterior, seguramente de su hija que pone: Inédito tachado.

136 Señala a continuación la revista Ciencia como reciente excepción.

137 AUUM, FMRF, caja 38, Anverso y reverso de la universidad española, 1947, 7 páginas mecanografiadas, versión manuscrita del mismo texto en caja 51, citas p. 3. 
En 1948 encontramos «el proyecto de creación en Montevideo de una universidad Hispano-Americana ${ }^{138}$, idea que patrocinan importantes sectores españoles republicanos del Uruguay y que puede revestir gran importancia para los universitarios españoles. Aparte del apoyo financiero que dichos sectores españoles prestan a esta idea, para que sea viable será necesario también obtener el del Gobierno uruguayo y el de la Unesco, y para obtenerlos se están realizando ya gestiones» ${ }^{139}$. La cuestión sigue abierta y la encontraremos en otros momentos bajo diferentes ropajes ${ }^{140}$. En 1949, en el período en el que se está gestando la creación del Ateneo Español de México ${ }^{141}$, se habla de un proyecto más amplio, la «Universidad española de América», en las reacciones al discurso de Jesús Ruiz del Río sobre "Significación política del Instituto de Cultura Hispánica", que tuvo lugar en el ciclo «Los viernes de Las Españas» en respuesta a la penetración de la España oficial en Latinoamérica $^{142}$. Una realidad tangible del compromiso intelectual de los republicanos acogidos en México es la intensísima labor cultural, científica y de comunicación que emprendieron, entre cuyos exponentes destaca la revista Ciencia, en la que publicarán muchos de los exiliados en materias científicas $^{143}$.

138 Ruiz-Funes, tras su reciente viaje, expuso a la junta este proyecto. Acta de la UPUEE, de 16 de enero de 1948 .

139 Actas UPUEE, 16 de enero de 1948, pp. 58-59.

140 Hay numerosas reacciones en el exilio a la acción cultural falangista. La colonia española en México no es solo republicana, y resulta de interés la forma de expresarlo de Wenceslao Roces: «Hasta los abarroteros gachupines de Casino Español de México han encontrado su ideólogo «cultural» en el Martín Artajo ese, especie de viajante de comercio en «cultura» franquista. La anunciada creación del llamado Instituto Hispano-Mexicano de Cultura, sucursal en México del Instituto de la Hispanidad falangista -es decir, vehículo de propaganda y agresión del fascismo- es presentada por el embajador de la «cultura» del Pardo como «un instrumento para resolver (ipasmaos!) las necesidades espirituales» de la Honorable Colonia española en México, y naturalmente, como «una gran cruzada de cultura». Conferencia pronunciada el 25 de febrero de 1948, en el ciclo organizado por la Delegación del Partido Comunista de España en México, publicado en La Cultura de Nuestro Tiempo, Ediciones España Popular, México, D.F., 1948.

141 López Sánchez, 2009: 41-55.

142 "Actividades de Los amigos de Las Españas -Significación política del Instituto de Cultura Hispánica", Las Españas (México, enero 1949): 13. En esta breve reseña de la conferencia de Jesús Ruiz del Río, del 6 de octubre de 1949, se indica que Ruiz-Funes, entre otros, tomó la palabra contra el recién creado instituto cultural del franquismo, y que se acordó crear una «gran revista de artes, ciencias y literatura que sea el más alto exponente del espíritu español democrático».

143 Cobos, Pulgarín y Carapeto, 2002. 
Enfrentemos los discursos de la hispanidad vencedora de Ibáñez Martín, con los de la hispanidad desterrada publicados por Ruiz-Funes. En la apertura del curso 1939-1940, en la universidad central, Ibáñez Martín pronuncia el discurso «La universidad actual ante la cultura hispánica» y con el epígrafe titulado «La gran hora de la hispanidad» hace una alabanza al imperio y a la cultura dominadora:

Era ya la hora imperial de la hispanidad. Yo necesito recordar todo esto. Porque con ser tan claro se empeñaron en olvidarlo muchos de nuestros intelectuales. España tiene una tradición y una doctrina imperial universitaria. Cuando la multitud de Bolonia, cuyos doctores llevaron las varas del rico palio de oro bajo el que hizo su entrada, para ser coronado Rey de Romanos, nuestro César, gritaba: «iImperio, Imperio! ¡Viva nuestro Emperador Carlos!», la falange de nuestros intelectuales ganaban también batallas para la catolicidad de nuestra cultura en las aulas de Europa. En el siglo XVI salieron nuestras ideas como otras naves aventureras a conquistar el mundo para la inteligencia de España. A nuestra fuerza expansiva se rinden todas las Universidades... ${ }^{144}$.

La exaltación de las viejas glorias sirve para enmascarar la penuria de la universidad española. La misma parafernalia que mantendrá el preámbulo de la ley de ordenación universitaria de $1943^{145}$.

Ruiz-Funes también dedicó su trabajo «Ocaso de la Hispanidad»a reflexionar sobre el significado del término hispanidad, que durante una década había sustentado el discurso franquista. Para los exégetas del régimen «constituye la expresión de un nuevo sistema político que tiene fundamentos negativos, los contra, contra el Renacimiento y contra la Reforma; los antis: el imperio falangista es antidemocrático, antiliberal, anticapitalista, antisocialista, anticomunista, antisemita y antimasónico». Se pregunta, pues, cuál es su contenido positivo. El jefe del Estado ha definido los rasgos más relevantes de su imperio: «la fe antes que la paz y que el bienestar, como su fundamento espiritual; el traje negro y austero como su rango suntuario». Se trata de un imperio «sombrío», «oscurantista», un nuevo imperio Falangista que «ha realizado sus autos de fe, fusilando herejes y quemando libros y periódicos, y una asociación estudiantil, ante el crecimiento del protestantismo, ha abogado porque se resucite la Santa Inquisición» ${ }^{146}$.

144 Ibáñez Martín, 1939: 15-16.

145 Acerca de la ley de ordenación universitaria de 1943 véase un análisis en Peset, 1991. Sobre la gestación de la ley, Rodríguez López, 2002: 55-151. Así como, Rubio Mayoral, 2013: 206-215.

146 Ruiz-Funes, 1998: 224-225. También en Ruiz-Funes, 2006: 142-149. 
Explica el uso del discurso americanista para cubrir las vergüenzas de la génesis del régimen, «Hitler y Mussolini quedan sepultados en un pasado inconfesable...»y acierta con el juicio histórico futuro sobre la habilidad política de Franco para mantenerse en el poder, «El Generalísimo es flexible» ${ }^{147}$. También se detiene en lo que él llama el "Antiamericanismo» de la ciencia impuesta por parte del Estado falangista, de la obra de la censura, bajo el falso patriotismo democrático y el ilusionismo americanista:

Los ideales imperialistas de la hispanidad se han declarado incompatibles, por un nutrido coro de voces, entre las que figura la infalible del Caudillo, con el falso patriotismo democrático y con el ilusionismo predominante en América... El falso pacifismo democrático le ha tendido la mano y el iluminismo ha pretendido incorporar el traje negro y austero, las joyas de un empréstito, no sabemos si con el designio de borbonizar a la España de los Austrias, cuya continuidad se rompió durante siglos, para reanudarse con el Caudillo, nuevo Felipe II ${ }^{148}$.

Concluye preguntándose si los sucesos recientes son el ocaso de la hispanidad o el ocaso de la democracia. Resuelve que los hechos «abogan en pro del ocaso de la hispanidad...» ${ }^{149}$.

Podemos ir cerrando con las palabras de Ruiz-Funes, tomadas de la ponencia que dirigió en las Jornadas de cultura española de 1950 ya mencionadas ${ }^{150}$. En el apartado VII de las conclusiones titulado «Sobre la política cultural de la España libre del futuro», se posicionan sobre un concepto de hispanidad diferente al del franquismo ${ }^{151}$ :

... finalidad de exclusiva difusión cultural, absolutamente exenta de afanes proselitistas de cualquier índole y mucho menos impulsos de predominio, debe ser objeto de especial atención el cumplimiento, como un deber fraterno, de intercambios y colaboraciones culturales en toda su amplitud con los pueblos de América.

Para terminar tomamos unas reflexiones esbozadas sobre el redescubrimiento de América por los exiliados, diferenciando entre «pueblos permeables y pueblos absortos» y considerando con orgullo su destierro «nos arrojaron de la tierra de nuestros padres; nos habéis dado una tierra para nuestros hijos»", pero ahora no es la conquista, sino un encuentro con una cultura rica y unas

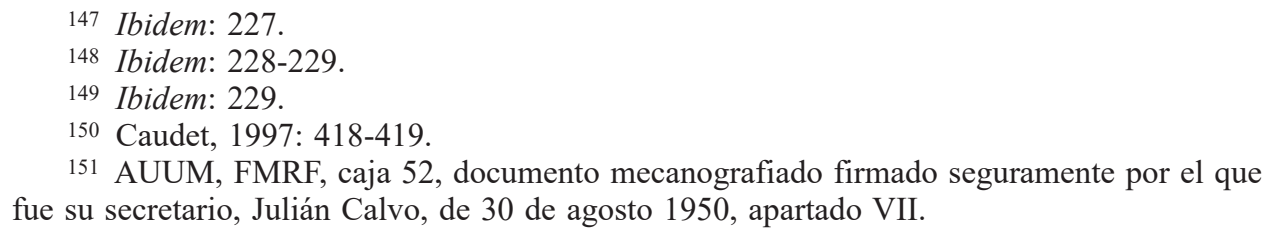

151 AUUM, FMRF, caja 52, documento mecanografiado firmado seguramente por el que fue su secretario, Julián Calvo, de 30 de agosto 1950, apartado VII. 
sociedades vibrantes, «sin carabelas, sin encomenderos, sin voluntad de imperio, no somos los invitados que imponen menú, ni hermanos, nada que ver con ellos. No gratitud, solo justicia» ${ }^{152}$. Mientras, Ibáñez Martín hablará de la América hispana como guardiana de las esencias, a la que «le incumbe mantener enhiesto el baluarte del espíritu ante la quiebra de los valores morales; le compete defender con brío la amenazada civilización cristiana, de la que fue y es ella el mejor portavoz» ${ }^{153}$.

\section{CONCLUSIONES}

La lucha desde el exilio contra los principios franquistas de reforma universitaria y del concepto de hispanidad con fines propagandísticos para el nuevo estado, son tratados a partir de las vidas cruzadas de estos dos políticos situados en bandos opuestos. Hemos intentado presentar distintas facetas de dos personajes de nuestra historia universitaria, José Ibáñez Martín y Mariano Ruiz-Funes, que debido al drama de la guerra quedaron, al mismo tiempo, separados y unidos, desde posturas políticas opuestas: vencedor y vencido. A lo largo de tres décadas se encuentran forzosamente vinculados por sus trayectorias políticas con continuas interferencias. Dos versiones distintas de la historia que ahora se analizan y contrastan, con las que aportamos una pieza más sobre la historia de la universidad y el pensamiento americanista, unida a dos voces relevantes en el panorama intelectual y político español. En la universidad franquista la hispanidad supondrá un impulso a los estudios americanistas, que serán contrarrestados desde el exilio. Los intelectuales exiliados no quieren que la España de Franco monopolice el significado de hispanidad en su propio provecho. En el CSIC se dotarán con presupuesto generoso los centros americanistas y el régimen se encargará de financiar la historia de América ${ }^{154}$. La inversión en actos y publicaciones sobre la hispanidad servirá para acallar las acusaciones desde el exilio de vacío cultural. Franco había ganado la guerra y se había apoderado de las instituciones, pero aún se podía luchar en el campo de las ideas. A pesar de que uno se apoyaba

152 AUUM, FMRF, caja 52, Anotaciones para el discurso homenaje a Salvador Azuela de 1951.

153 Ibáñez Martín, 1947: 11. Existe otro interesante paralelismo entre ambos personajes alrededor de la interpretación de El Quijote, sobre el que en este trabajo no nos podemos extender. En 1947 se conmemora el IV Centenario del nacimiento de Cervantes, y a él dedicarán publicaciones y actos culturales tanto la intelectualidad republicana exiliada como las instituciones culturales franquistas, entre ellos Ruiz-Funes e Ibáñez Martín.

154 Pasamar Alzuria, 1991: 152-157. 
en la contundente fuerza de su ministerio y el boletín oficial, y el otro solo disponía de la palabra y una debilitada esperanza hacia un futuro democrático que no llegaría a ver.

\section{BiBLIOGRAFÍA}

Alted Vigil, Alicia, "Bases político-ideológicas y jurídicas de la Universidad franquista durante los Ministerios de Sáinz Rodríguez y primera época de Ibáñez Martín (1938-1945)", Juan José Carreras Ares y Miguel Ángel Ruiz Carnicer (eds.), La universidad española bajo el régimen de Franco (1939-1945), Zaragoza, Institución Fernando el Católico, 1991: 95-124.

Arco, Manuel del y Equipo Mundo, Los 90 ministros de Franco, Madrid, Dopesa, 1971.

Arenal, Celestino del, "La hispanidad y la política exterior del franquismo", La política exterior de España hacia Iberoamérica, Madrid, Editorial Complutense, 1994: 29-68.

Avilés Faré, Juan, La izquierda burguesa y la tragedia de la II república, Madrid, Comunidad Autónoma, 2006.

Ayala, José Antonio, "Un político murciano de la II República: Mariano Ruiz-Funes, ministro de Agricultura", Murcia en la II República, Murcia, Academia Alfonso X el Sabio, 1984: 211-260.

Balbín Lucas, Rafael de, "Ibáñez Martín y la investigación humanista”, Arbor, 75/289 (Madrid, 1970): 13-16.

Baldó Lacomba, Marc, "Represión franquista del profesorado universitario", Cuadernos del Instituto Antonio de Nebrija, 14 (Madrid, 2011): 31-51.

Blasco Gil, Yolanda y Mancebo, M. ${ }^{\mathrm{a}}$ Fernanda, Oposiciones y concursos a cátedra de historia en la universidad de Franco (1939-1950), Valencia, Universitat de València, 2010.

Blasco Gil, Yolanda y Saorín Pérez, Tomás, "Rastro y ausencia del penalista Mariano Ruiz-Funes", Anuario de Historia del Derecho Español, 83 (Madrid, 2013): 773-826.

Blasco Gil, Yolanda y Saorín Pérez, Tomás, Las Universidades de Mariano Ruiz-Funes: la lucha desde el exilio por la universidad perdida, Murcia, Editum, Ediciones de la Universidad de Murcia, 2014.

Bullón de Mendoza, Alfonso, José Calvo Sotelo, Barcelona, Ariel, 2004.

Cañellas Mas, Alberto, "Las políticas del Instituto de Cultura Hispánica, 1947-1953", Historia Actual Online, 33 (invierno 2014): 77-91. 
Caudet, Francisco, El exilio republicano en México. Las revistas literarias (19391971), Madrid, Fundación Banco Exterior, 1997.

Claret Miranda, Jaume, El atroz desmoche. La destrucción de la Universidad espanola por el franquismo, 1936-1945, Barcelona, Crítica, 2006.

Cobos Bueno, José Miguel, Pulgarín Guerrero, Antonio y Carapeto, Cristina, "Ciencia: Revista hispano-americana de ciencias puras y aplicadas (1940-1975)", Llull: Revista de la Sociedad Española de Historia de las Ciencias y de las Técnicas, 25/53 (Madrid, 2002): 329-368.

Delgado Gómez-Escalonilla, Lorenzo, Imperio de papel. Acción cultural y política exterior durante el primer franquismo, Madrid, CSIC, 1992.

Diego Pérez, Carmen, "Intervención del primer Ministerio de Educación Nacional del franquismo sobre los libros escolares", Revista Complutense de Educación, 10/2 (Madrid, 1999): 53-72.

Esperabé de Arteaga, Enrique, Diccionario enciclopédico ilustrado y crítico de los hombres de España, Madrid, Artes Gráficas Ibarra, 1956.

Fernández Burgueño, Vicente y Rodríguez Guerrero, Carmen, "El instituto San Isidro (1901-1936). La edad de plata de la enseñanza oficial", Participación educativa, número extraordinario (Madrid, 2011): 211-224.

González Cuevas, Pedro Carlos, "Hispanidad”, Javier Fernández Sebastián y Juan Francisco Fuentes (coords.), Diccionario político y social del siglo XX español, Madrid, Alianza, 2008: 617-623.

Gracia Arce, Beatriz, Trayectoria política e intelectual de Mariano Ruiz-Funes: República y exilio, Murcia, Editum, Ediciones de la Universidad de Murcia, 2014.

Guirao López, José, El Casino de Murcia, 1847-1994. Su historia, significación socio-cultural y turística en la vida murciana, todos los presidentes desde su fundación, Murcia, J. Guirao, Grafirmar, 1994.

Ibáñez Martín, José, La universidad actual ante la cultura hispánica, Madrid, Universidad Central, 1939.

Ibáñez Martín, José, Dos discursos. I. Discurso en la Academia de Jurisprudencia. II. Discurso en el VI Consejo Extraordinario del SEU, Madrid, Talleres Gráficos Samarán, 1940a.

Ibáñez Martín, José, Hacia un nuevo orden universitario, Valladolid, Universidad de Valladolid, 1940b.

Ibáñez Martín, José, Hacia un renacimiento de los estudios eclesiásticos, Salamanca, Universidad Pontificia de Salamanca, 1940c.

Ibáñez Martín, José, Hacia una nueva ciencia española, Madrid, Real Academia Española, 1940d.

Ibáñez Martín, José, Un año de política docente, Barcelona, Universidad, 1941a. 
Ibáñez Martín, José, "Palabras a Hispanoamérica”, Voces de la hispanidad, Madrid, Afrodisio Aguado, Asociación Cultural Hispano-Americana, 1941b: 209-217.

Ibáñez Martín, José, El sentido político de la cultura en la hora presente, Madrid, Universidad Central, 1942.

Ibáñez Martín, José, Realidades universitarias en 1944, Valencia, Universidad, 1944a.

Ibáñez Martín, José, Renacimiento científico en la investigación y en la docencia, Valencia, Universidad, $1944 b$.

Ibáñez Martín, José, "Prólogo”, Antonio Martín de Cámara, En camino: guiando una empresa científica, Madrid, Consejo Superior de Investigaciones Científicas, Arbor, 1946.

Ibáñez Martín, José, “Símbolos hispánicos del Quijote”, Revista Nacional de Educación, 74 (Madrid, 1947): 9-23.

Ibáñez Martín, José, Diez años de servicios a la cultura española: 1939-1949, Madrid, Magisterio Español, 1950.

Ibáñez-Martín Mellado, José Antonio, José Ibáñez-Martín: en el centenario de su nacimiento, Zaragoza, Institución "Fernando el Católico", 1998.

Lida, Clara E. (comp.), México y España en el primer franquismo, 1939-1950, México, D.F., El Colegio de México, 2001.

López Sánchez, José María, "El ateneo español de México y el exilio intelectual republicano", Arbor, 735 (Madrid, 2009): 41-55.

López Sánchez, José María, "Entre Madrid y México: Entre hispanidad o hispanoamericanismo", Los refugios de la derrota, Madrid, CSIC, 2013: 249-261.

Marcilhacy, David, "La hispanidad bajo el franquismo. El americanismo al servicio de un proyecto nacionalista", Xosé M. Nuñez Seixas y Stéphane Michonneau (eds.), El imaginario nacionalista español en el franquismo, Madrid, Casa de Velázquez, 2014: 73-102.

Martí Ferrándiz, José J., Poder político y educación. El control de la enseñanza (España 1936-1975), Valencia, Universidad de Valencia, 2001.

Martínez Barrios, Elena, Epistolario de la embajada nacionalista Latinoamericana 1937-1928 (Análisis histórico político e institucional), Zaragoza, Cátedra de Historia del Derecho y de las Instituciones de la Universidad de Málaga, 1998.

Miguel, Amando de, Sociología del Franquismo: Análisis ideológico de los Ministros del Régimen, Barcelona, Euros, 1975.

Montero, José R., La CEDA. El catolicismo social y político en la II República, 3 vols., Madrid, Ediciones de la Revista de Trabajo, 1977. 
Moreno Fernández, Luis Miguel, "La Asociación Católica Nacional de Propagandistas y el diario La Verdad de Murcia durante la II República", Anales de Historia Contemporánea, III, 1984: 189-213.

Moreno Fernández, Luis Miguel, Acción Popular Murciana: la derecha confesional en Murcia durante la II República, Murcia, Servicio de Publicaciones e intercambio científico de la Universidad de Murcia, 1987.

Morla Lynch, Carlos, Informes diplomáticos sobre la guerra civil española, Santiago de Chile, RIL editores, ADICA, 2003.

Otero Carvajal, Luis E. (coord.), La destrucción de la ciencia en España. Depuración universitaria en el franquismo, Madrid, Universidad Complutense, 2006.

Padilla Bolívar, Antonio, Los hombres de Franco. 161 personajes clave en el franquismo, Madrid, Flor de Viento, 2008.

Pardo Sanz, Rosa, Con Franco hacia el imperio. La política exterior española en América Latina, 1939-1945, Madrid, UNED, 1994.

Pasamar Alzuria, Gonzalo, Historiografía e ideología en la posguerra española: la ruptura de la tradición liberal, Zaragoza, Universidad de Zaragoza, 1991.

Pérez Montfort, Ricardo, Hispanismo y Falange, los sueños imperiales de la derecha española, México, Fondo de Cultura Económica, 1992.

Peset, Mariano, "La ley de ordenación universitaria de 1943", Juan José Carreras Ares y Miguel Ángel Ruiz Carnicer (eds.), La universidad española bajo el régimen de Franco (1939-1945), Zaragoza, Institución Fernando el Católico, 1991: 125-146.

Portero, Florentino, Franco aislado. La cuestión española, 1945-1950, Madrid, Aguilar, 1989.

Puig-Samper Mulero, Miguel Ángel (ed.), Tiempos de investigación: JAE-CSIC, cien años de ciencia en España, Madrid, CSIC, 2007.

Rodríguez López, Carolina, La universidad de Madrid en el primer franquismo. Ruptura y continuidad (1939-1951), Madrid, Instituto Antonio de Nebrija, Dykinson, 2002.

Rubio Mayoral, Juan Luis, "Modelos docentes para el nuevo régimen. Estudio normativo desde la política de la Universidad española (1943-1970)", Cuestiones pedagógicas, 22 (Sevilla, 2012/2013): 203-230.

Ruiz-Domènec, José Enrique, España, una nueva historia, Madrid, Gredos, 2009.

Ruiz-Funes, Manuel (ed.), Mariano Ruiz-Funes, comentarista de su tiempo, Murcia, Dirección General de Archivos y Bibliotecas, 2006.

Ruiz-Funes, Mariano, "Discurso", Libro de la Primera Reunión de Profesores Universitarios Españoles Emigrados, La Habana, 1944: 207-2011. 
Ruiz-Funes, Mariano, "La corrupción en la universidad española", Las Españas, 7 (México, 1947a): 16.

Ruiz-Funes, Mariano, "Anverso y reverso de la Universidad española", Ultramar revista mensual de cultura, 1 (México, 1947b): 4 y 29.

Ruiz-Funes, Mariano, "La esencia de la universidad", Novedades, 2.696 (México D.F., martes 13 de mayo 1947c): 4.

Ruiz-Funes, Mariano, "Principios universitarios", Novedades, 4.732 (México D.F., 9 de diciembre de 1952): 4.

Ruiz-Funes, Mariano, “Ocaso de la hispanidad”, Jorge Domingo y Róger González (eds.), Sentido de la derrota. Selección de textos de escritores españoles exiliados en Cuba, Barcelona, Gexel, 1998: 224-299.

Sáinz Rodríguez, Pedro, La escuela y el estado nuevo, Burgos, Hijos de Santiago Rodríguez, 1938.

Sapag Muñoz de la Peña, Pablo, Propaganda republicana y franquista en Chile durante la guerra civil española, Madrid, Universidad Complutense, 1996.

Sapag Muñoz de la Peña, Pablo, Chile, frente de combate de la Guerra Civil española. Propaganda republicana y franquista al otro lado del mundo, Valencia, Centro Francisco Tomás y Valiente, UNED Alzira-Valencia, 2003.

Suárez, Ángel (pseudónimo de Colectivo 36), “Introducción a la ACNP”, Sáez Alba (pseudónimo), La ACNP: La otra cosa nostra. La Asociación Católica Nacional de Propagandistas y el caso de El Correo de Andalucía, París, Ruedo Ibérico, 1974.

Tapia, Daniel, “Disparadero de Las Españas, Dámaso y la realidad”, Las Españas, 11 (Madrid, 1949): 15.

Tuñón de Lara, Manuel, Tres claves de la segunda República, Madrid, Alianza, 1985.

Valenciano Gaya, Luis, El rector Loustau y la universidad de Murcia, Murcia, Academia Alfonso X, 1979.

Valender, James y Rojo Leyva, Gabriel, Las Españas: historia de una revista del exilio, 1946-1963, México, El Colegio de México, 1999.

Vegas Latapie, Eugenio, Los caminos del desengaño. Memorias políticas 2, 1936 1938, Madrid, Tebas, 1987.

Viñas, Ángel (ed.), Al servicio de la República. Diplomáticos y guerra civil, Madrid, Marcial Pons, 2010.

Fecha de recepción: 16 de diciembre de 2014.

Fecha de aceptación: 16 de febrero de 2015. 


\section{University and "Hispanidad". The interwoven paths of minister José Ibáñez Martín and exiled teacher Mariano Ruiz-Funes spanning three decades}

We consider the struggle against two of the policies of the Franco regime fought from intellectual republican exile: university reform and appropriation of the concept of "Hispanidad" for the regime's propaganda purposes. Both issues are traced through the lives and careers of two leading political figures starting in Murcia in the 1920s, when one was chair of criminal law and the other of secondary education. We explore their political activism on opposite sides, service on international missions during the war, and conclude with Mariano Ruiz-Funes's work at the Union of Spanish Teachers Abroad in Mexico and José Ibáñez Martin's position as head of the new Ministry of National Education. The analysis focuses on their own articles and speeches, published as books or in journals, including those preserved in their private archives, and considers how they reflect two different Spains.

KeY WORDS: Spanish Republican exile; Spanish university; university in exile, ministers of Franco regimen; fight against Franco's dictatorship; Hispanidad. 